\title{
Trade-off between formal and informal care in Spain ${ }^{\aleph}$
}

\author{
Sergi Jiménez-Martín•
}

Cristina Vilaplana Prieto*

May 24, 2008

\begin{abstract}
The remarkable growth of older population has moved long term care to the front ranks of the social policy agenda. Understanding the factors that determine the type and amount of formal care is important for predicting use in the future and developing long-term policy. In this context we jointly analyze the choice of care (formal, informal, both together or none) as well as the number of hours of care received. Given that the number of hours of care is not independent of the type of care received, we estimate, for the first time in this area of research, a sample selection model with the particularity that the first step is a multinomial logit model.

With regard to the debate about complementarity or substitutability between formal and informal care, our results indicate that formal care acts as a reinforcement of the family care in certain cases: for very old care receivers, in those cases in which the individual has multiple disabilities, when many care hours are provided, and in case of mental illness and/or dementia. There exist substantial differences in long term care addressed to younger and older dependent people and dependent women are in risk of becoming more vulnerable to the shortage of informal caregivers in the future. Finally, we have documented that there are great disparities in the availability of public social care across regions.
\end{abstract}

JEL Codes: I1, J14.

Keywords: formal care, informal care, caregiver, dependent.

\footnotetext{
"We are very grateful to David Casado, Pilar Garcia-Gómez, Juan Oliva, and workshop participants in University of Barcelona, FEDEA and XXXII SAE congress for helpful comments. Financial help from project SEJ2005-08783-C04-01 is gratefully acknowledged.

- Universitat Pompeu Fabra and FEDEA.

- Universidad Católica San Antonio de Murcia and FEDEA.
} 


\section{Introduction}

It is commonly accepted that family caregivers provide a vast quantity of long-term care to elderly dependent people. An important issue is the balance between what the family and state respectively are doing for old people and to what extent the responsibility for old people in need is a shared one.

The main purpose of this paper is to shed some light on the trade-off between formal and informal care of dependent people as well as to analyse the relationship between the choice of care and the number of hours of care provided. Formal care is defined as paid or free of charge attention provided by public or private institutions and non profit-making organizations, whereas informal care refers to the attention provided by family members, friends and neighbours. Some authors have considered that informal care is a source of better-quality care because of affective linkages and because it helps the patient to continue living in the community (Keating et al., 1997).

The growth of elder population cohorts during last decades has implied an increase in the proportion of people who suffer mental or physical disabilities for doing daily living activities in developed countries, and Spain constitutes a paramount example. Figure 1 represents the trend of the fraction of population older than 40 years in Spain. The fraction of population between 65-80 years has steadily grown since 1900, and in 2007 it represents $16.7 \%$ of the total population ${ }^{1}$. Likewise, the fraction of population +80 years has increased from $0.6 \%$ in 1900 to $4.5 \%$ in 2007. These facts are explained by the decrease in the mortality rate, both infant mortality and elderly (+70) population.

Figure 2 shows that the participation of age-related or ageing expenditures, health and social expenditures with respect to GDP has increased in recent years, especially since 1999. However, still ageing expenditure to GDP ratio is lower than the average EU-25 (see Table A.1 for a comparison). Spain is positioned in the group of countries with lower ageing expenditure (with Germany, France and Portugal, 0.3\%; Ireland, 0.2\%; Greece and Italy, 0.1\%) and very far from Austria (0.7\%), United Kingdom (1\%), Denmark (1.1\%) and Sweden (2.6\%).

A line in the literature has analysed informal care from the perspective of public expenditure, that is, they have praised its advantages as a free of charge source of care. Nonetheless, they have ignored other type of costs associated with informal care, such as, psychological effects, loss of leisure time, decrease in labour supply and worsening of household finances (Fast et al., 1999; Van Exel et al., 2004; Hirst, 2005). In this line Zarit and Eggenbeen (1995) have suggested that it would be desirable to force back public health

\footnotetext{
${ }^{1}$ Life expectancy at birth in 2005 was 83.5 (female) and 77.0 (male) with respect to 35.7 (female) and 33.9 (male) in 1900. Life expectancy after 65 years has increased from 15.3 (female) and 13.1 (male) in 1960 to 21.3 (female) and 17.3 (male) in 2005.
} 
expenditure through a redirection of dependent long-term care from the public sphere to the family core. However, the family ability to carry most of the burden may be limited due to several sociodemographic changes, such as, smaller family size, increasing female participation in the labour market and higher divorce rates. ${ }^{2}$ However, in future years, immigration may play an important role in the provision of formal care. In fact, between 1994 and 2004, (Informal Support Survey; IMSERSO) the percentage of private household employees has increased form $2,29 \%$ to $8,89 \%$, from which $30,1 \%$ (in 2004) where immigrants.

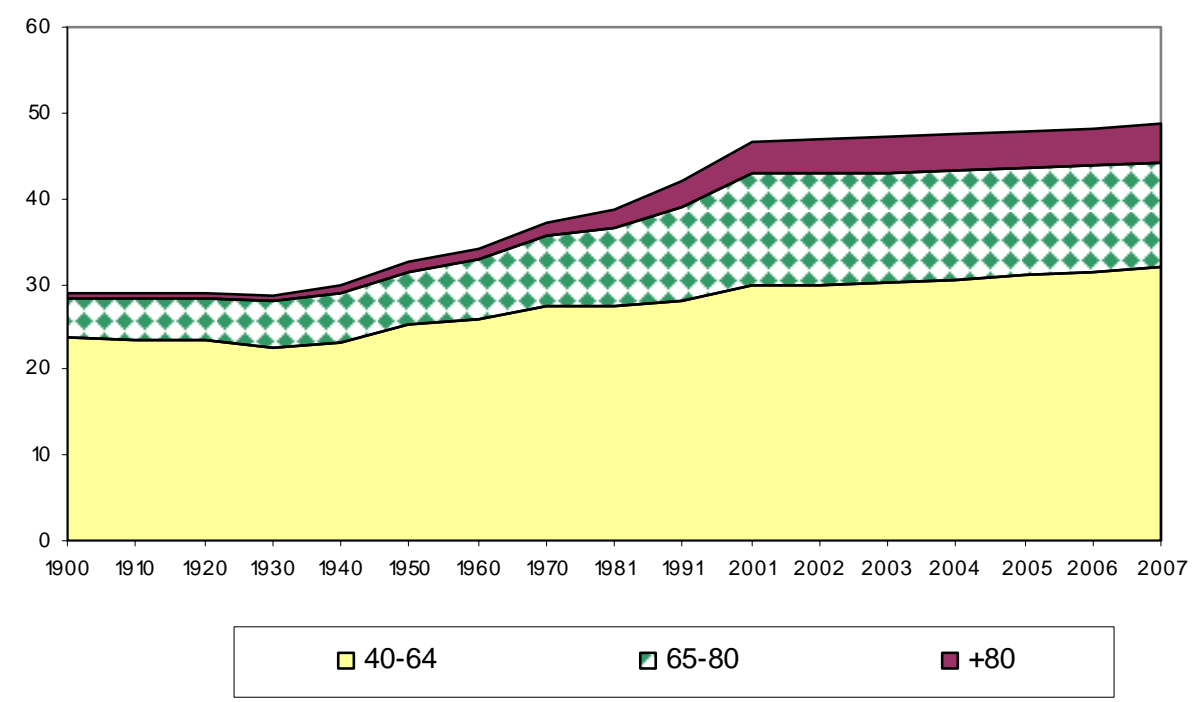

Figure 1: Trends of the Spanish Population aged +40. 1900-2007

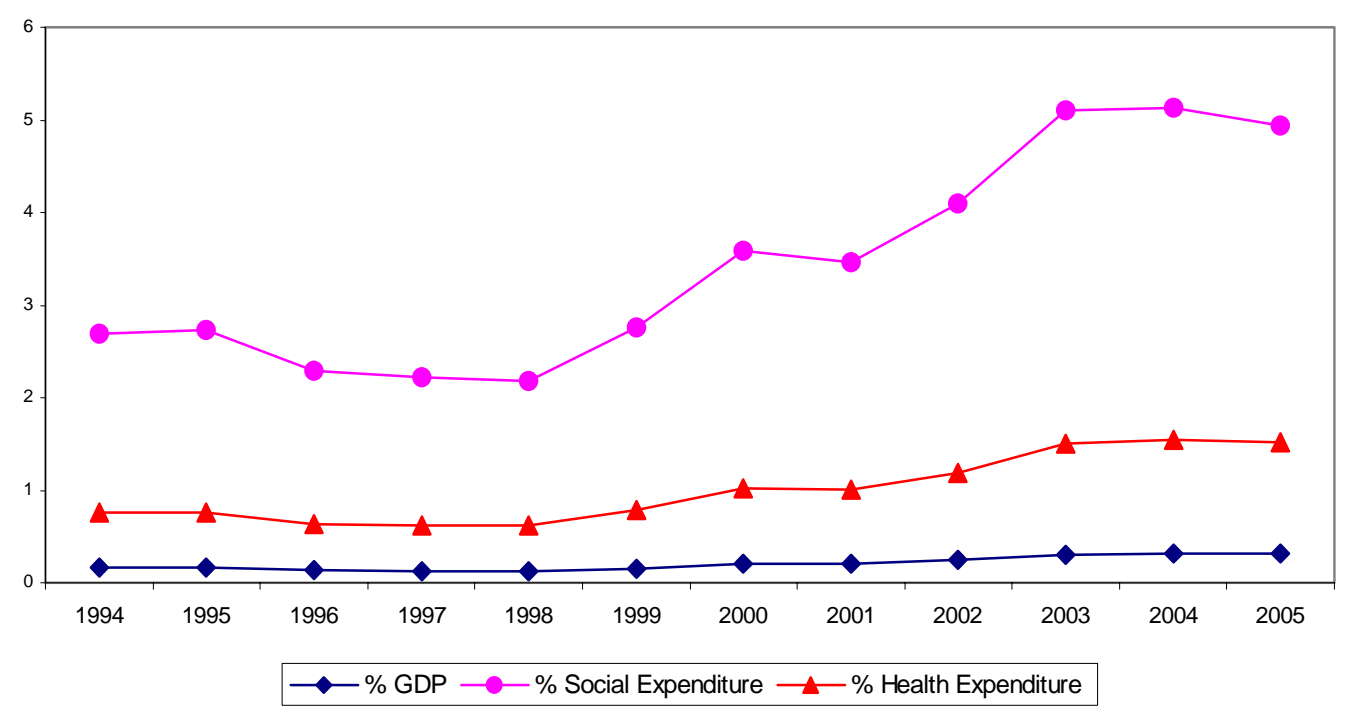

Figure 2. Trends of the ageing related expenditure in Spain

\footnotetext{
${ }^{2}$ All three indicators have suffered dramatic changes in recent decades: the birth rate (for 1000 inhabitants) have decreased from 18.8 in 1975 to 10 in 2006, with a minimum of 9.2 in 1998; female participation rate has increased from $28.8 \%$ in 1976 to $49.4 \%$ in the fourth quarter of 2007; finally, the divorce rate (for 100 marriages) has increased from 4.7 in 1980 to 44.9 in 2006.
} 
However, the relatively modest figures for Spanish ageing expenditure may be related to "family ties". There is solid evidence that supports the idea of strong family ties in Mediterranean countries and weak family ties in the Scandinavian ones (Bolin et al., 2007). Hence, it becomes more urgent to study the relationship between formal and informal care in Spain. If government trust in the ability of informal caregivers and not increases public ageing expenditure, then the characteristics and number of informal caregivers can affect the wellbeing of dependent people in Spain more than in other European countries.

Regarding the existent economic literature about care to dependent people, there is a vexing question of whether formal caregiving hours (provided by clinical staff, nurses, physiotherapists) compensate, substitute, complement or reinforce informal caregiving hours provided by family members, friends or neighbors (Glazer, 1990; Chappell and Blandford, 1991; Mayall, 1993; Bass and Noelker, 1994; Denton, 1997). Four models for the relation between formal and informal care may be distinguished: compensatory, substitution, taskspecific and complementary.

The compensatory model (Cantor, 1979) postulates the substitution of one care system by the other, but following an order of preference. The dependent individual only resorts to the use of formal care (social care services or specialized private employees) when all sources of informal care have been exhausted. However, few empirical studies have confirmed this theory (Penning, 1990; Cantor, 1991; Chappell, 1991).

The substitution model (Greene, 1983), according to which as the patient receives formal care, the family decreases the amount of informal care provided. This argument is used by those economists who propose formal care rationing with the aim of controlling public health expenditure. But applied papers have found that, in most cases, family do not give up providing care when receive formal aid (Archbold, 1982; Christianson, 1988; Moscovice et al., 1988; Edelman and Hughes, 1990; Tennstedt et al., 1993). By contrast, Liu et al. (2000) and Langa et al. (2001) found that an increase in the reception of formal home care in the case of dependent who have already lived with adult children. Vittanen (2007) analyzed the relations between formal and informal care in 12 European countries and concluded that formal care substitutes for informal care supplied out of carereceiver's household but does not substitute for informal care of dependent's co-resident relatives.

The task-specific model was proposed by Litwak (1985). According to this model, formal and informal care are different but complements. It sustains that informal caregiver (a woman in most cases) is more suitable for day-to-day care (washing, dressing and undressing, eating and drinking) while formal care is set aside for more technological tasks. In contrast to the compensatory model, it is the nature of the task and not the will of the patient what determines who is the most appropriate for providing care (the family or the skilled 
professional). Several papers, such as Penning and Chappell (1990) and Fisher and Eustis (1994) have upheld this model.

Finally, the complementary model, a combination of the compensatory and the substitution model, was proposed by Chappell and Blandford (1991). When dependent needs exceed informal care resources, formal care provides the necessary support (Bass and Noelker, 1989; Edelman and Hughes, 1990; Denton, 1997). This is for example the case when informal caregivers need to make use of respite services. Chappell and Blandford (1991) spelt out two circumstances in which formal care is used in conjunction with informal care: when medical requirements are very complex and when the family goes through a critical situation. In this manner, formal care becomes involved when informal care realizes that cannot deal with everything by itself.

The lack of a cohesive conclusion is due to the idiosyncrasy of informal and formal care. Both types of care may happen simultaneously or one before and the other afterwards. This fact remarks the need for using econometric techniques to deal with the endogeneity inherent in formal and informal care. Our study extends the previous literature by examining how the choice of type of care affects the number of informal caregiving hours provided. To this end we estimate a two equation simultaneous model for the decisions of type of care and number of informal caregiving hours. Given that different types of formal care may affect differently the supply of informal care, we control the selection bias estimating a multinomial logit model (Bourguignon et al., 2004) and use the estimated residuals to control for endogeneity in the second step hour regressions. The first stage multinomial is tested again various other alternative specifications.

As regard specification results we have tested and not rejected the first stage multinomial models against several other alternatives (bivariate probit - FC vs IC- and trivariate probit - FC vs IC vs FIC). We have also excluded the possibility of independence between the choice of care and the number of hours provided. In fact, estimation under independence implies important differences in the estimated coefficients of several key variables of the model.

Our detailed results do not provide support to a unique theory of care. We have found evidence in favour of the Compensatory Model when is more probable that the dependent individual receives care from family members (if he is married or when household size increases) or when he suffers mental illness, dementia or disabilities for relating, communicating. In this case, the presence of informal caregivers may be more intense because of surveillance tasks or because given the nature of the illness, the family feels some kind of stigma and decides to face the situation in solitude. In this context, the diffusion of information about certain illnesses or the affiliation to associations of dependent's relatives could help to complement informal care with formal one. It is quite worrying (and even inefficient) that 
family members carry all the burden by themselves, because these disabilities usually present an unfavorable prognosis due to their association to degenerative diseases. Also, the Task Specific Model and the Complementary Model are supported in those circumstances when the degree of severity increases, when dependent has moved to receive a better medical treatment or has received a rehabilitation treatment. Then, the informal caregiver looks for formal care either to be helped with daily living activities or to alleviate the caregiver burden.

The rest of the paper goes as follows. In section 2 we describe the source of data and provide some descriptive statistics. In section 3 we propose a model of choice of care and caregiving hours, following Bourgingnon et al (2004), and validate it against other alternatives. In section 4, we estimate the model for the whole sample and four different subsamples (men, women, younger and older dependent people). And, finally, section 5 offers some concluding remarks.

\section{Data}

The dataset consists of information from the Disabilities, Deficiencies and Health Status Survey (DDHSS) drew up by the National Institute of Statistics in 1999, with the objective of estimating the amount of Spanish resident people who suffer any disability and identifying risk factors associated with health status.

To design the sample we have followed a two-step procedure. First, using the Disabilities and Deficiencies Questionnaire we select those individuals who answer in the affirmative to the question: "Do you suffer any kind of disability?," understanding as disability "a limitation for performing daily living activities that is going to last more than one year". Second, we focus on individuals older than 40 years old. Although many studies have focused on elder population (+65 years) (Ettner, 1996; Charmichael and Charles, 2003), we have observed that the amount of "young” people with disabilities is not negligible ${ }^{3}$. The final sample (+40 years with any disability) contains 17.442 observations.

We have defined three binary dependent variables: "informal care" (IC) that takes the value 1 if the individual only receives help from relatives (co-resident or not), friends or neighbors (6.216 observations); "formal care” (FC) if the individual only receives help from employees, public administration or private organizations ${ }^{4}$ (562 observations) and "formalinformal care" (FIC) if the individual receives help from both types of care (1.002

\footnotetext{
${ }^{3}$ There are 1.442 individuals (584 male, 838 female) aged between 40 and 64 years old, who need a caregiver for doing daily living activities. In fact, some previous evidence has suggested the earlier onset of some degenerative diseases. According to data from Fundación Alzheimer España and Asociación Parkinson Madrid, around 2.5\% of Alzheimer patients are younger than 55 years old and approximately $20 \%$ of Parkinsonism' cases are diagnosed before 50 years old.

${ }^{4}$ The survey indicates whether formal care provider belongs to public social services, has been hired from a private firm or is a household employee. In the last case, we do not know if the individual has any specific knowledge (nursery) or he is only entitled to the surveillance of the patient.
} 
observations). This implies that there are 9.662 individuals who suffer a disability but do not need or receive any type of care.

Respondents who declare to suffer any disability are required to give more details. There is a list of 36 disabilities (see the Appendix for a description), which, for the purpose of this paper, have been categorized in personal or instrumental disabilities for daily living activities (PADL and IADL, respectively) ${ }^{5}$, following the recommendations of the Federal Interagency Forum on Aging Related Statistics (2000). In any case, the interviewed must indicate the degree of severity and the prognosis associated to each disability. Preliminary analysis suggests that there is not a linear relation between the number of disabilities and the number of caregiving hours [The results of this exploration are available on request]. For that reason, we have defined six binary variables ( 3 for PADL and 3 for IADL) that take the value 1 if the individual suffers two, three, or more than three disabilities.

Apart from information about disabilities, the survey contains a list of specific pathologies, from which we have selected mental illness ${ }^{6}$, arthritis, muscular, dystrophy, multiple sclerosis, stroke, cerebral palsy ${ }^{7}$, dementia and Parkinsonism, due to the important limitations they usually involve for doing daily living activities.

With respect to the sociodemographic characteristics of the carereceiver, we have considered those variables that may have an influence on the type of care received, either because they directly affect health status (age and sex) or because they have implications over the generation of informal networks (marital status, number of household adults). Given that some authors have documented a positive correlation between income and availability of formal care (Branch et al., 1981) we control for household income as well as for the level of education of the dependent.

From a theoretical point of view, when informal care is not available or is not enough, public social services behave as subsidiary responsible for the attention of the dependent. With the aim of taking into account geographical differences in the provision of formal care, and given that the DDHSS does not include information about the price of formal care received, we have defined a set of dummy variables to denote the place of residence and the size of the municipality.

\footnotetext{
${ }^{5}$ PADL include disabilities for getting up and down, standing up, moving inside home, washing oneself, controlling physical needs, dressing and undressing, eating and drinking. IADL include disabilities for carrying not heavy objects, using utensils and tools, clutching small things with hands and fingers, moving without way of transport, driving own vehicle, do the shopping, cooking, washing and ironing clothes, cleaning the house and looking after the well-being of the family.

${ }^{6}$ Mental illnesses refer to bipolar disorders, depression, anxiety, stress, schizophrenia, whereas dementia is related to all possible kinds of dementia (senile, Alzheimer, due to AIDS, brain tumour, brain damage). ${ }^{7}$ Brain-vascular diseases are the second cause of death for male and the first one for female, according to the Fundación Española de Enfermedades Neurológicas.
} 
In Figure 3 we appreciate that as people get older the percentage of non-dependent decreases and at the same time, the fraction of people who need some type of care increases. The amount of individuals who, conditional on having a disability or a deficiency, receive IC raises from $24 \%$ at 40 years old to $70 \%$ at 90 years old. In the second place, FIC represents $12.5 \%$ at the age of 90 . By contrast, the trend for FC is increasing from 60 to 80 years old (6\%) and decreasing afterwards (1.8\% for the interval 96-99 years).

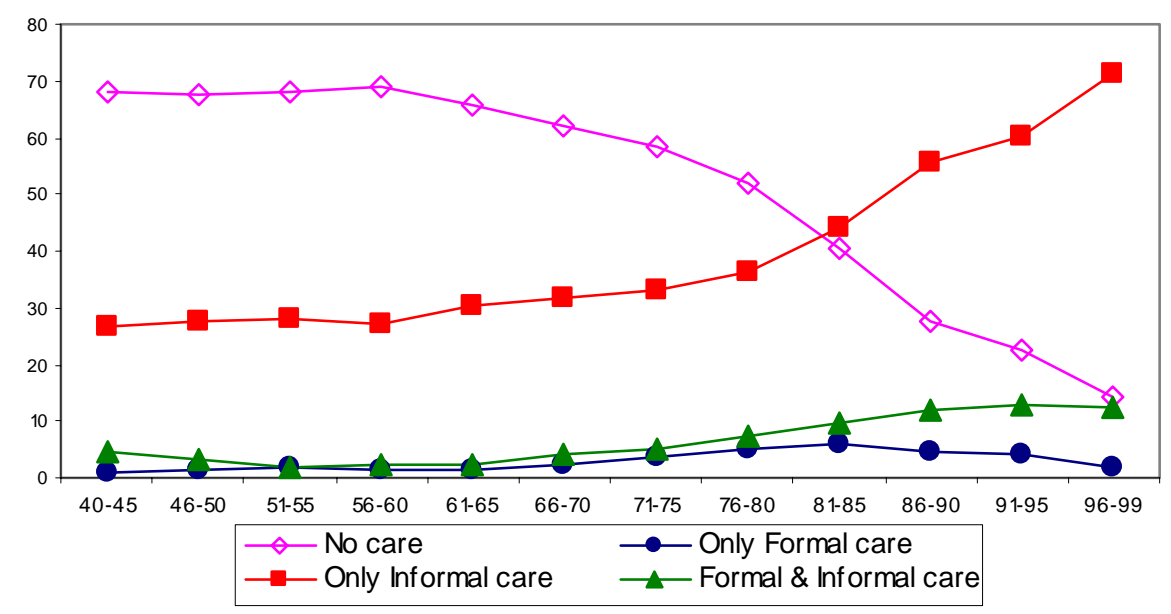

Figure 3. Distribution of the Population by type of care

The distribution of the type of care by level of household income (Figure 4) shows that for high income levels, IC decreases while FIC increases. In fact, for the intervals (2.343.9 €3.906.6 $€$ ] and more than 3.906.6 $€$, the percentage of FIC increases from $28.5 \%$ to $50 \%$. On the other side, low-income households [264.5 €, $390.6 €$ ] attain the maximum level of FC. It is convenient to clarify that poorest and richest households do not use the same kind of FC. Wealthiest families prefer to hire household employees and private sector services ${ }^{8}$.

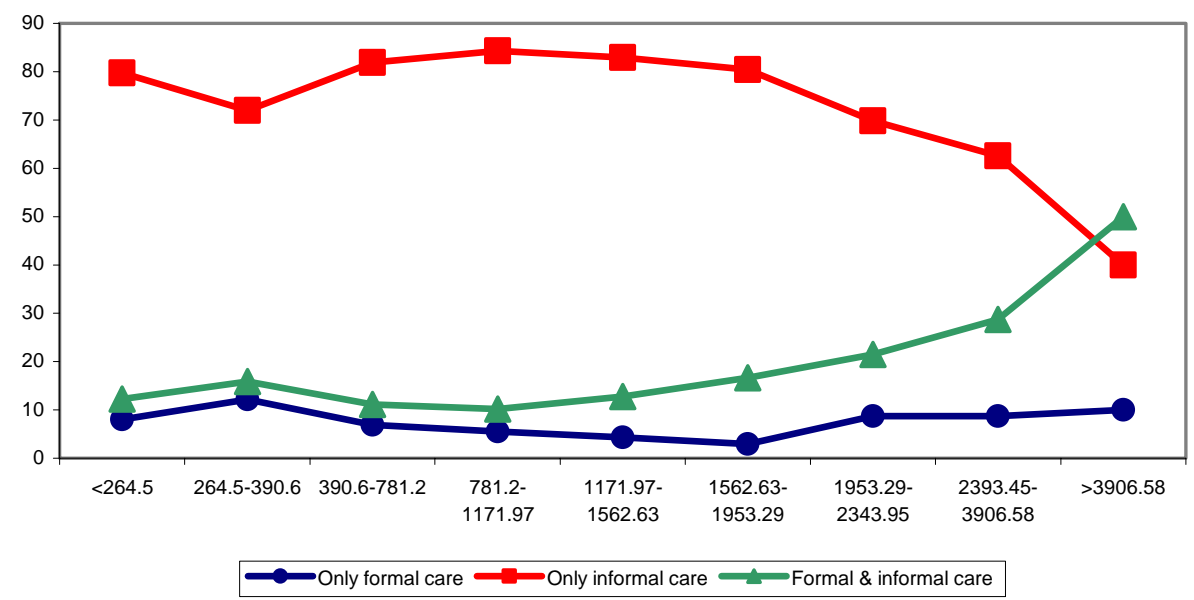

\footnotetext{
${ }^{8}$ As a matter of fact, the household's employees rate for the whole sample is $0.7 \%$ whereas it goes up to $20 \%$ for households with more than $2344 € /$ month.
} 
Figure 4. Distribution of the type of care by brackets of monthly household income (€)

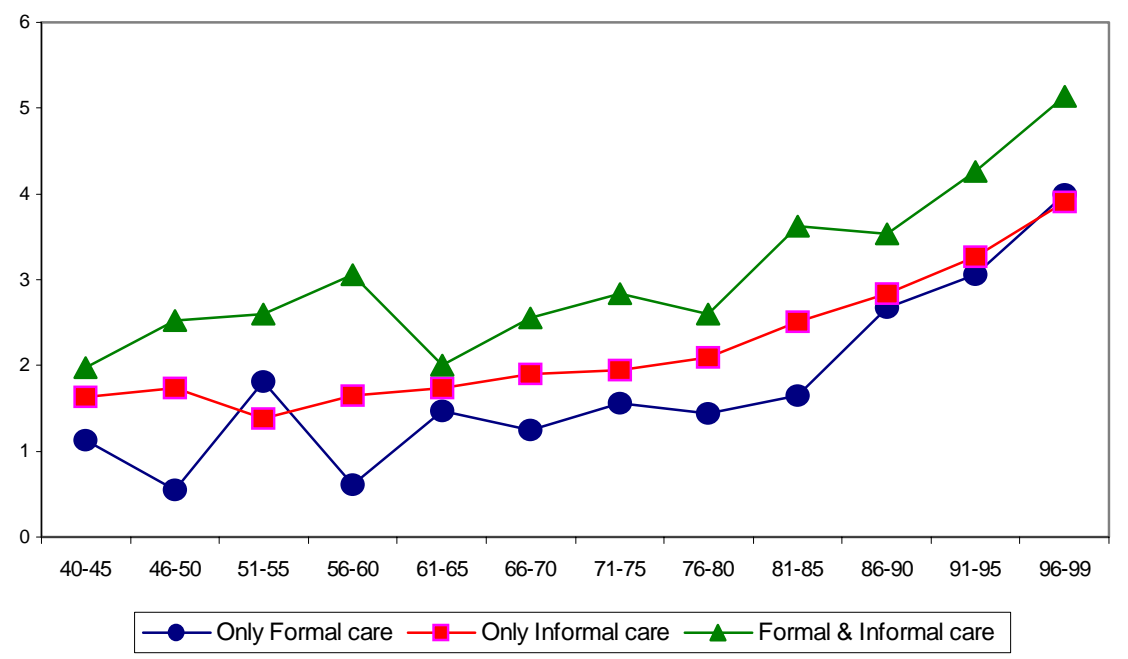

Figure 5. Number of personal disabilities for daily living (PADL) by age.

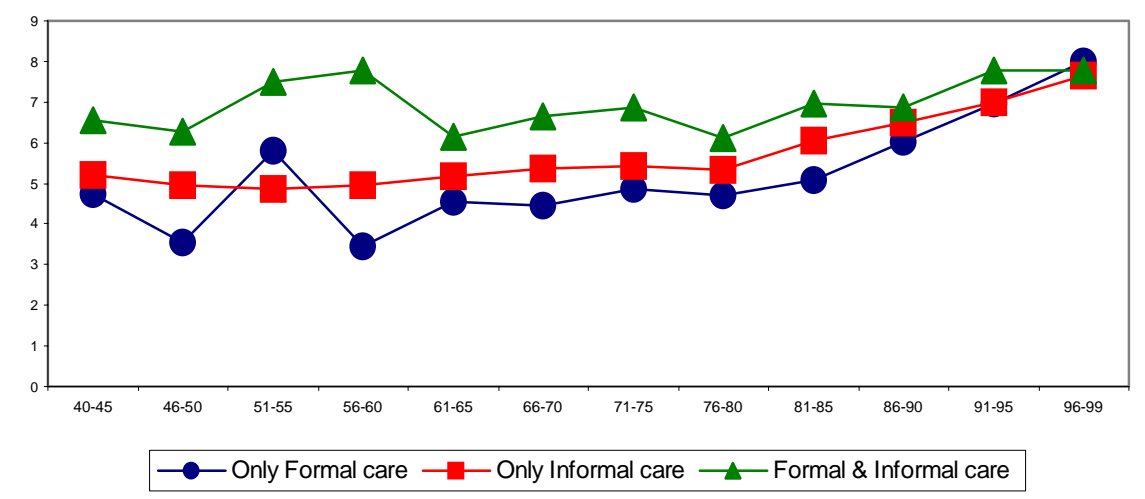

Figure 6. Number of instrumental disabilities for daily living (PADL) by age.

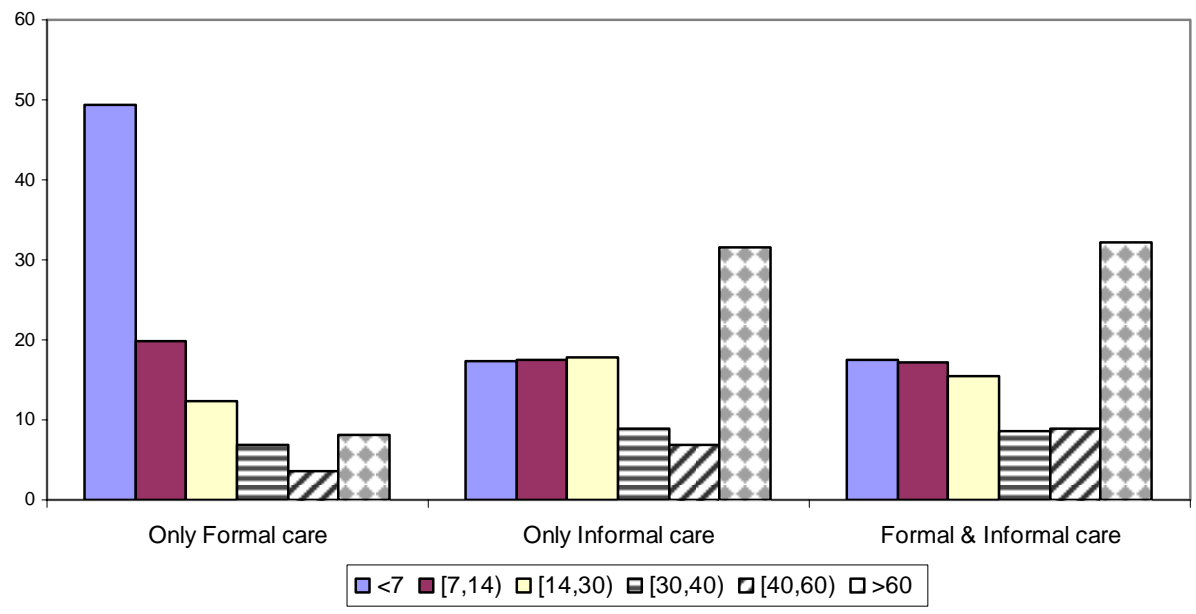

Figure 7. Distribution of the number of weekly caregiving hours by type of care.

The average number of disabilities either PADL or IADL (see figures 5 and 6, respectively) increases with age and is much higher for dependent people who receive FIC. In 
Figure 6, we also observe that the distance among the three types of care decreases as the dependent becomes older. Finally, Figure 7 represents the distribution of caregiving hours by type of care ${ }^{9}$. The mode for those that only receive FC is 7 or less hours. Alternatively, the mode for those who receive IC or FIC is 60 hours or above.

\subsection{Descriptive statistics}

Tables 2 and 3 of the Appendix show detailed descriptive statistics for the explanatory variables. Very old dependent people (aged 80-89 or 90-99 years old) are more prone to receive FIC. Not married dependent people (single, widowed, separated/divorced) usually receive FC.

Education and income are key determinants of the type of care. Educated individuals tend to receive a higher fraction of formal care. Among those that receive IC, 59\% have finished elementary education and only $1.5 \%$ of them have obtained a college degree. The same figures for dependent people with FC are $48.9 \%$ and $8.9 \%$ respectively. As we shall see later, this may be because either education is a proxy variable for the level of income, or because as people become more educated it turns out easier for them to access to the available information.

For the three types of care, more than $30 \%$ of dependent people are receiving a retirement benefit and those who receive IC show the highest concentration of disability benefits (both contributive and non-contributive). FIC is mainly devoted to dependent belonging to high-income households (more than $1562.6 € /$ month), while IC is concentrated among medium-low income households (390.7 $€$ to $1562.6 €$ per month). On the other hand, the highest fraction of FC appears in very low-income households (264.5 € to $390.7 €)^{10}$.

With respect to the size of municipality, the smaller the township size, the higher the percentage of dependent with IC. Moreover, families with children are more inclined to take care of a dependent relative. This fact may point to the existence of intergenerational caregiving networks (grandparents that live together with adults and children), and the substitution of FC by IC. However, as it will exposed later, modern life characteristics may threaten the traditional family core around a dependent individual.

Regarding the list of pathologies considered, dependent without any type of care show the lowest percentages for all the illnesses. For the three types of care, stroke and arthritis have the highest incidence rate. Carereceivers with FIC show the highest percentage for mental illnesses (25.9\%), head injury (12.2\%), dementia (13.3\%), change of house (12.2\%, to receive better medical treatment or having an adapted dwelling) and rehabilitation treatment (23.7\%).

\footnotetext{
${ }^{9}$ We do not know the distribution of care hours between formal and informal in those cases in which the individual receives formal and informal care. Furthermore, we do not know how many hours are devoted to each type of disability (PADL and IADL).

${ }^{10}$ This may be due to the fact that public social services for dependent people do not only take into account the severity of physical and mental disabilities, the availability of close relatives, and the living conditions but also personal financial resources.
} 
We could consider that when family receives information/advice (from doctors, nurses or therapist) about the type of aids they may apply for (home centers, day centers, respite centers, adapted transport...) and method of financing (free of charge, combined payment) the probabilities of applying for one of these aids increase considerably.

As for disabilities, carereceivers with IC suffer mainly disabilities for moving outside home (86\%), doing housework (78\%), maintaining body postures (51\%) and taking care of oneself (46\%). The incidence of disabilities for relating to people (30\%) and communicating (30\%) is much higher among those who receive FIC. Among those who receive FC, disability for doing housework is the most prevailing one (91\%). This circumstance may be explained because in many regions, home care services ${ }^{11}$ emphasize home help rather than personal care.

Dependent people with FIC suffer more PADL disabilities (3.1), followed by those with IC (2.2) and finally by those with FC (1.6). A similar ranking is obtained when looking at IADL disabilities (6.8, 5.61, 5.0, respectively).

With respect to the degree of severity, FIC carereceivers exhibit disabilities with the highest degree of severity (98\% are very severe, $95 \%$ can not do the activity), and for the three types of care, around $70 \%$ of carereceivers suffer disabilities with unfavorable prognosis. On the other side, people who do not need a caregiver generally report the lowest percentage of disabilities with stable or unfavorable prognosis.

\section{A model of choice of care and hours}

\subsection{The Bourguignon Model}

The choice of the number of care hours $(H)$ is not independent of the type of care $(C)$. It is not a simple choice in which the dependent individual chooses the caregiver and the number of hours to be provided. Instead, it is more complex because there are several decision-makers involved. First, family members may or may not adjust their lifestyle to the dependent needs. Second, some private professionals may be hired by the family or by the patient, and finally, the Public Administration offers special services for non-institutionalized dependent people (home care, Telecare, day care centers and respite services). Because of these reasons, we have developed a two simultaneous equations model for estimating the decisions of type of care chosen and number of care hours received.

\footnotetext{
${ }^{11}$ Home Care Service is a program for helping dependent people and their families, without substituting the role of the informal caregiver. It is divided into four different areas: home help (shopping, cleaning the house, washing the clothes), personal care, psychological attention (to improve self-esteem and lower dependency from others) and attention to family members (strengthen family cohesion). With the exception of País Vasco, Cataluña and Rioja, in the rest of Autonomous Communities, most of the time is devoted to home help rather than to personal care activities (Observatorio de Personas Mayores, 2000).
} 
We define an "outcome equation" (1a) that indicates the number of caregiving hours received and a "selection equation" (1b) which identifies the type of care chosen. There is a categorical variable $j$ which denotes the choice of the type of care among the set of alternatives $\{0=$ no care (omitted category), $1=$ formal care, $2=$ informal care, $3=$ formal $\&$ informal care $\}$. In this way, each one of the outcome variables is only observed for a single value of the selection variable.

$$
\begin{aligned}
& H_{j}=X \beta_{j}+\varepsilon_{j} \\
& C_{j}=Z \alpha_{j}+u_{j}
\end{aligned}
$$

$\{\mathrm{j}=0,1,2,3\}$

where $\varepsilon_{j}$ verifies that $E\left[\varepsilon_{j} \mid X, Z\right]=0$ and $V\left[\varepsilon_{j} \mid X, Z\right]=\sigma^{2}$. The vector $Z$ represents the set of explanatory variables for the care alternatives and the vector $\mathrm{X}$ contains the determinants for the number of hours ${ }^{12}$.

Without loss of generality let us assume for the rest of the model that the observed outcome belongs to the first category $\left(\mathrm{C}_{1}>\max { }_{j \neq 1}\left(\mathrm{C}_{\mathrm{j}}\right)\right)$. Thus we concentrate on the consistent estimator of $\beta_{1}$. The problem that we face is the estimation of $\beta_{1}$ and $\left(\alpha_{\mathrm{j}}\right)^{\prime}$ s taking into account that the error term $\varepsilon_{1}$ may not be independent from all the errors in the model. This situation would induce correlation between the explanatory variables and the residual term in the outcome equation. For this reason, OLS applied to the selected sample can be inconsistent. As a consequence, we have a selection bias model as in Heckman (1979), with the difference that the selectivity criterion is given by a multinomial logit model rather than by a univariate probit.

Several alternatives have been put forward in the econometric literature to identify the parameters of this model. Lee (1983) proposed a generalization of Heckman (1979) method. His approach is quite simple and only requires the estimation of one parameter in the error correction term. However, it imposes very restrictive assumptions about the structure of the covariance between $\varepsilon_{1}$ and the error terms of the selection equation. To avoid this problem, Dubin and McFadden's (1984) introduced a method which does not require the imposition of any constraint between $\varepsilon_{1}$ and the error terms of the selection equation, but they restrict $u_{j}$ to the family of Gumbell’s distributions. More recently, Dahl (2002) has developed a semiparametric approach, but whose practical implementation is nearly computationally impossible as the number of alternatives to be estimated increases. Finally, Bourguignon et al. (2004) proposed a variation to Dubin and McFadden method. In this paper we follow the latter approach.

\footnotetext{
${ }^{12}$ We identify the model by imposing some exclusion restrictions, that is, variables in $\mathrm{Z}$ that are not in $\mathrm{X}$. For example: the variables "education" and "relation with economic activity" are included in Z but not in $\mathrm{X}$ because it may gather the effect of available information about social services for dependent people..
} 
Bourguignon et al. (2004) considered a variation of Dubin and McFadden's (1984) estimation method that allows $\varepsilon_{1}$ to be a linear combination of normal distributions, and as a result, $\varepsilon_{1}$ also follows a normal distribution.

$$
\begin{aligned}
& u_{j}^{*}=\Phi^{-1}\left(G\left(u_{j}\right)\right) \quad j=0,1,2,3 \\
& \varepsilon_{1}=\sigma_{1} \sum_{j} \tilde{\rho}_{j} u_{j}^{*}+\eta_{1}
\end{aligned}
$$

where $\Phi$ is the cumulative standard normal, $G$ is the cumulative Gumbell distribution and $\tilde{\rho}_{j}$ is the correlation coefficient between $\varepsilon_{1}$ and $u_{j}{ }^{*}$. For each $j$, it is assumed that the expected value of $\varepsilon_{1}$ and the error term $u_{j}^{*}$ are linearly related ${ }^{13}$, where $\eta_{1}$ denotes a residual term orthogonal to all $\left(u_{j}^{*}\right)^{\prime}$ s and such that $\mathrm{E}\left[\eta_{1}\right]=0$. This implies that a crucial assumption in this specification is that the Independence of Irrelevant Alternatives hypothesis holds ${ }^{14}$. Substituting the error term of equation (1a) by its conditional expectation plus a residual term, we get the following expression:

$$
\begin{aligned}
& H_{1}=X \beta_{1}+\sigma_{1}\left[\tilde{\rho}_{1} \delta\left(P_{1}\right)+\sum_{j>1} \tilde{\rho}_{j} \frac{P_{j}}{P_{j}-1} \delta\left(P_{j}\right)\right]+v_{1} \\
& \delta\left(P_{j}\right)=\int u_{j}^{*} g\left(u_{j}+\log P_{j}\right) d u \quad j=0,1,2,3 \\
& P_{j}=\frac{\exp \left(Z_{j} \alpha_{j}\right)}{\sum_{s} \exp \left(Z_{s} \alpha_{s}\right)} \quad j=0,1,2,3
\end{aligned}
$$

where $g$ is the Gumbell density distribution, $P_{j}$ is the probability that alternative $j$ is chosen, and $v_{1}$ has zero-mean and is orthogonal to all equation terms. Therefore, OLS may be applied in this equation to obtain a consistent estimation ${ }^{15}$ of $\beta_{1}$.

Consequently, we can consider the resulting model as a two-step process. In the first step, we estimate a multinomial logit model for care choice, using as explanatory variables (age, sex, marital status, main breadwinner, level of education, relation with economic activity, monthly household income, number of children, number of household adults, variables related to disabilities and illnesses, size of municipality and place of residence). Caregiving alternatives have been defined as a categorical variable (1 “only formal care”, 2 "only informal care”, 3 "both formal and informal care"). Not receiving any type of care is the reference group (0). Using the estimated coefficients $\left(\hat{\alpha}_{j}\right)$ we obtain the predicted probabilities $\left(\hat{P}_{j}\right)$. These estimated probabilities take on all the information gathered in the multinomial model. Thereby,

\footnotetext{
${ }^{13}$ The linear combination assumption is based on the fact that all $u_{j}^{*}$ are independent among them.

${ }^{14}$ Smith et al. (2004) and Ewoudou and Vencatachellum (2006) provide an interesting discussion of the empirical advantages of the selectivity correction method proposed by Bourguignon et al. (2004) even when a non-linear specification is present in the model.

${ }^{15}$ See Bourguignon et al. (2004) for a detailed explanation.
} 
$\delta\left(\hat{P}_{j}\right)$ provides a consistent estimation of the residual expected value in the outcome equation (1a). Its sign indicates the direction of the selection bias resulting from the selection of individuals in the modality of care from which the caregiving hours equation is estimated as opposed to all other types of care taken together.

Afterwards, a model for the number of caregiving hours is estimated by weighted least squares to consider the possibility of heteroskedasticity due to selectivity. For getting the standard errors, a bootstrap with 50 replications has been applied to take into account the twostep procedure. We have considered that the number of caregiving hours is explained by individual factors (age, sex, illnesses and other health variables, number, type and severity of disabilities), socio-economic (marital status, household income, number of children adult members) and geographical factors (size of municipality).

\subsection{Alternatives to the Bourguignon Model}

Before estimating the Bourguignon model we want to validate the suitability of the multinomial logit for the first step of the model. First, we have performed Hausman test ${ }^{16}$. Results indicate that we cannot reject the IIA hypothesis, thereby indicating that distinguishing between FC, IC and FIC is not only analytically, but also econometrically appropriate. Likewise an F test support the validity of the exclusion restrictions we have imposed (mean breadwinner, level of education, relation with economic activity and place of residence).

We also have performed other specification tests comparing the goodness of fit of the multinomial logit for the first step regression with a bivariate probit ${ }^{17}$ and a trivariate probit ${ }^{18}$. Results of the Akaike Information Criterion (AIC) and Bayesian Information Criterion (BIC) (see Table A below) show that the multinomial logit model reports the lowest values for the AIC although the bivariate probit reports a slightly lower BIC. If we repeat the same exercise for the different subsamples (men, women, young and old), we confirm that the AIC is always smaller for the multinomial model ${ }^{19}$

Table A. Comparison of goodness of fit statistics for the first step model

\footnotetext{
${ }^{16}$ The null hypothesis says that the odd-ratios are independent of other alternatives, that is, if a subset of choices is irrelevant, their omission from the model will not change the estimations obtained with the remaining alternatives. But if the estimated coefficients are not independent from the omitted alternatives, the parameters estimated will be inconsistent.

${ }^{17}$ We have defined two binary variables (FC and IC) if the individual receives formal or informal care. For those who do not receive any type of care, both variables take the value 0. For those who receive FIC, both variables take the value 1 . Estimation results are available upon request.

${ }^{18}$ We have defined three binary variables (FC, IC, FIC). For those who do not receive any type of care, the three of them take the value 0 . Estimation results are available upon request.

${ }^{19}$ AIC and BIC pursue different objectives. AIC tries to minimize the difference between the true distribution and that of a candidate, whereas BIC tries to maximize the posterior model probability. Yang (2003) has shown that is not possible to unit the rivalry between both criteria, that is, consistency and minimax rate cannot be shared.
} 


\begin{tabular}{lcc}
\hline ALL SAMPLE & AIC & BIC \\
\hline Multinomial logit & $22.313,67$ & $24.131,063$ \\
Bivariate probit & $22.558,278$ & $23.777,639$ \\
Trivariate probit & $24.497,788$ & $26.338,481$ \\
\hline MEN & \\
\hline Multinomial logit & $7.053,7266$ & $8.341,7855$ \\
Bivariate probit & $7.081,212$ & $7.951,3369$ \\
\hline WOMEN & & \\
\hline Multinomial logit & $15.465,927$ & 16837,145 \\
Bivariate probit & $15.589,413$ & 16510,814 \\
\hline YOUNGER & & $9.307,4584$ \\
\hline Multinomial logit & $8.066,8873$ & $8.896,798$ \\
Bivariate probit & $8.062,8585$ & \\
\hline OLDER & & 15.916 .269 \\
\hline Multinomial logit & $14.615,409$ & $15.605,789$ \\
Bivariate probit & $14.731,322$ & \\
\hline
\end{tabular}

\section{Results}

\subsection{Trade-off between formal and informal}

After estimating the multinomial logit for the choice of care, we have computed the predicted probabilities of receiving each type of care for a determined base case: male, age 8089, married, with elementary education, household income between 390,6€ and 1.171,97€ per month, suffering one PADL and one IADL and living in Cataluña. Table 5 reports the predicted probabilities for the base case and the marginal effects. The probability of receiving IC for the base case is the highest (0.278) in comparison with the probabilities of receiving some kind of formal care combined or not with informal one $(0,025$ for FC and 0,014 for FIC). These probabilities provide evidence in favour of the Compensatory model, because the favourite source of care for the baseline is IC, which is consistent with Bolin et al. (2007) results in that family ties are stronger in Mediterranean countries

The higher the level of education achieved, the lower probability of receiving IC (-3.7\% for high school and $-10.5 \%$ for college degree). In this sense, education of the dependent individual (which is also related with the level of education of his environment) may act as a measure of the cost of applying for social services ${ }^{20}$ for people with disabilities (Bass and Noelker, 1987). Or alternatively, more educated potential caregivers may have a higher opportunity cost.

\footnotetext{
${ }^{20}$ For example, there is plenty of information about social services for dependent people available through Internet (Imserso Mayores, Servicio de Información sobre Discapacidad, InfoElder,...).
} 
Married dependent people show lower probability of receiving only FC. Some studies (Chappell and Blandford, 1991) consider that having a couple guarantees the reception of informal care. However, IC may be offered by other members of the family, such as adult children (Stoller and Earl, 1983; Ettner, 1995). In fact, the estimated coefficients indicate that each adult member increase the probability of receiving IC by $2.32 \%$. The net of informal caregivers may improve dependent's health by listening to medical instructions, transporting the patient to appointments and may lead to noticing health problems more quickly (Task-specific model).

If the dependent individual receives a non contributive permanent disability benefit, the probability of receiving IC increases by $6.1 \%$. By contrast, contributive disability benefit is not significant for any type of care. Perhaps the reason is that to receive a non contributive disability benefit it is necessary a degree of disability greater than $65 \%$ and be lacking of enough income, but one might receive a contributive disability benefit with a degree of disability of at least 33\%.

The probability of receiving FC decreases for the three lowest intervals (-1,5\%). At the same time the probability of receiving FIC increases as household income increases $(0,4 \%$ for $1.172 €-1.953,3 €$ and $4,8 \%$ for more than $3.906,6 €)$. It should be pointed that FC received by individuals at lower income intervals usually comes from public social services (day centers, home care service), whereas individuals in higher income intervals do not qualify for public FC and have to rely on private FC (which may or may not co-reside with the dependent).

People who have benefited from a rehabilitation treatment or have changed of house to receive a better medical treatment show a significant increase in the probability of receiving the three types of care, although the probability of receiving IC increases more $(8,7 \%$ for change of house and 2,4\% for rehabilitation treatment). This fact may indicate that without the emotional support of informal caregivers, the dependent does not dare to start a different therapy, and thus reinforces the Complementary Model.

\subsection{Choice of care by age and gender}

Figure 8 shows the choice of care by age and gender. The number of individuals is showed on the top of each column. As we can see, the percentage of IC is higher for men and young dependent although in absolute terms there are more women and old people. Comparing the probabilities for the base case ${ }^{21}$ we observe that the probability of receiving FC is higher for women than for men $(0,15$ against 0,014$)$ and the probability of receiving IC is higher for old dependent (70-99 years) with respect to the youngest (40-69 years) $(0,291$ against 0,135$)$. The lowest probability of receiving FIC goes with young dependent $(0.00071)$ whereas women attain the highest one (0.034)

\footnotetext{
${ }^{21}$ For men and women: individual aged 80-99, married, one PADL and one IADL, living in Cataluña. For young and old: man, married, one PADL and one IADL, living in Cataluña.
} 


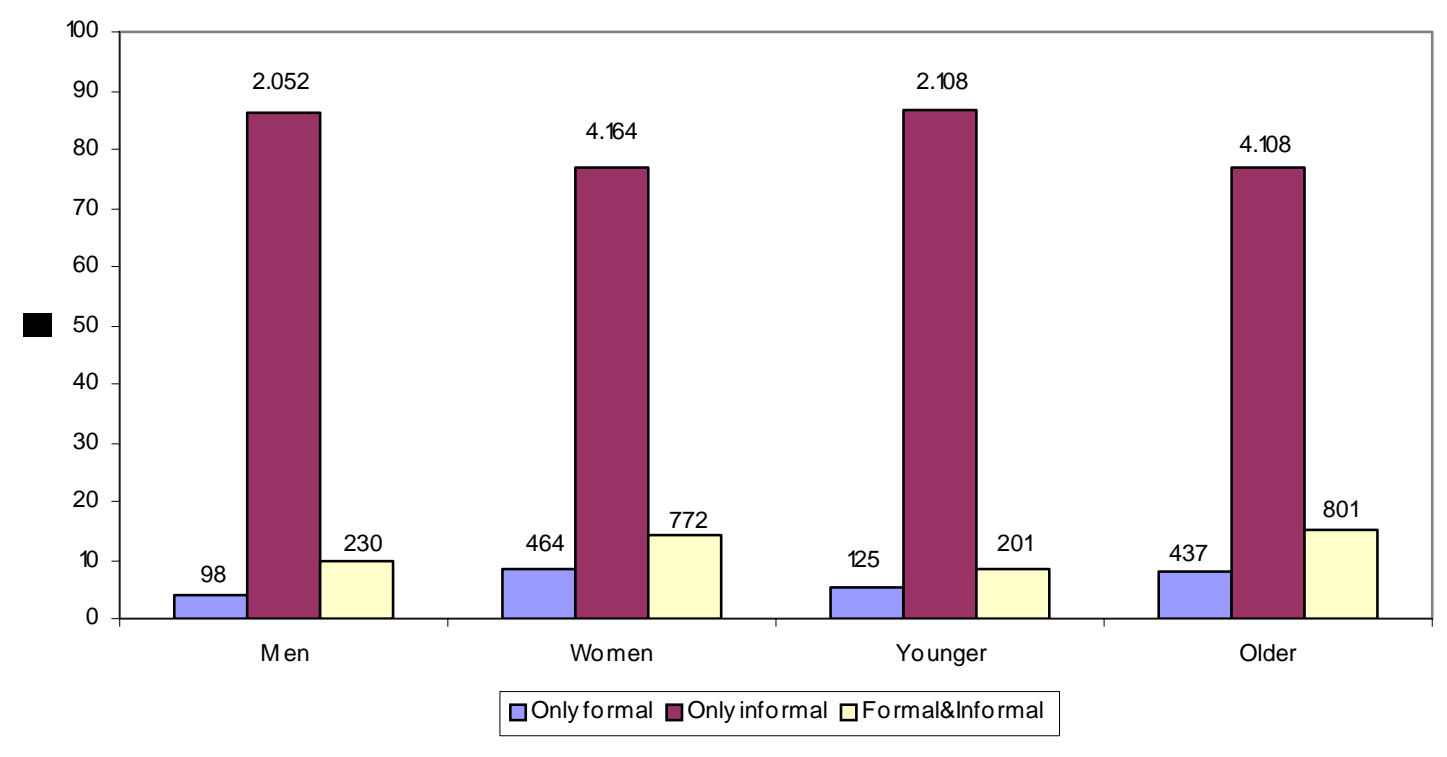

Figure 8. Choice of care by age and gender.

\section{Comparison Men and Women}

In Table 5 we present the results of the first stage multinomial model by gender. The probability of receiving FC decreases by $7 \%$ for married men and by $5 \%$ for married women. Being divorced decreases the probability of IC by $13 \%$ for men but it is not significant for women. On the other hand, the number of co-resident adults slightly decreases the probability of FC for men, but each additional adult increases the probability of IC for women by 4,5\%. Two factors may explain why husbands of disabled women play a much lesser role than wives of disabled men. First, husbands of disabled women may be less able to provide care because they may be older ${ }^{22}$ and more disabled than wives of disabled men. Second, husbands may be less prepared to fulfill the social role of caregiver without the presence of disability (Lee et al, 1993).

Disabilities for seeing, hearing and communicating decrease the probability of FC for men and women. These disabilities may be offset, to a certain extent, with technical devices (hearing aid, special telephones, sound alarm systems), and with the appropriate use of these elements, dependent people do not need to be supervised permanently.

Suffering three or more IADL disabilities increase the probability of receiving FC by 3\% for men and between 11 and 14\% for women. Although we could think that gender differences related to IADL disabilities are connected to houseworking, support for grocery and preparing meals, we do not believe that this is the case because the gender difference is consistently observed across other IADL disabilities such as using public transport, moving around home and using utensils and tools. If the severity of the disability is recoverable, stable

\footnotetext{
${ }^{22}$ In 2006, average marriage was 33.8 for men and 30.8 for women (27.4 and 24.5, respectively in 1975).
} 
or can go worse, the probability of using IC increases for both genders, but the coefficients are more than twice for men than for women.

\section{Comparison young and old}

Tables 6 presents the results dividing the sample by age groups: young (50-69) and old (70+). Living in a municipality with less than 10.000 inhabitants increases (decreases) the probability of receiving IC for young (old) dependent individuals. For young carereceivers it may be easier to find a caregiver of the same generation (brothers, sisters), whereas for the case of old dependent people it is more difficult to find available caregivers because adult children could have migrated to another place looking for a job.

For the subsample of young dependent, we observe a negative sign for the marginal effect corresponding to disabilities for seeing, hearing, communicating, or having two or three PADL disabilities. Moreover, the highest marginal effect (in absolute value) corresponds to IC, which means that young dependants are less prone to use this type of care with respect to FC and FIC. However, for the old subsample, the probabilities of receiving the three types of care increases with the number of PADL or IADL disabilities. These differences may be explained because younger dependent people seek self-control and flexibility, emphasizing living as meaningfully and normally as possible. Many young dependent people perceive medication management, help with catheters and ostomies like an extension of daily living activities, which can be done without the supervision of a formal caregiver, once the patient has learnt to do everything by himself. By contrast, older dependent people have accepted that certain decisions are beyond their control (for example, home care is based on schedules, which means that bath time and bedtime may be different from their wishes).

With respect to cognitive impairments, the probability of using IC when suffering dementia or mental illness increases around 9\% for young dependent, whereas it increases by $19 \%$ for old dependent. Moreover, suffering disability for remembering information or executing orders decreases the probability of IC for young dependent and diminishes the probability of FC for the old subsample. In this case, the difference in the social services approach between seniors with dementia and younger people with cognitive impairment suggests that ageism and not dementia is the root of the distinction. The Spanish Association of Mental Illness Relatives ${ }^{23}$ claims that already exists a stigma associated to mental patients and their relatives, and call for an egalitarian treatment with the rest of dependent people,

If the severity of the disability is stable or can go worse the probability of receiving IC increases $5,2 \%$ and $6,4 \%$ respectively, for young, and $8,1 \%$ and $10,8 \%$ for old. The same effect

\footnotetext{
${ }^{23} \mathrm{http}: / /$ www.feafes.com/FEAFES/Noticias/Tratamiento+integral.htm
} 
is observed for the variable severity, 4,7\% (13\%) and 7\% (12\%) for moderate and very severe disabilities in the regression for young (old) dependent people.

Extremadura is the region with the higher probability of IC for young people and not for old, which may be explained because is the third region with more elder people living alone (21,3\%). By contrast, Cantabria, Navarra and Ceuta show the highest probability for IC for old dependent. These results could be related to the characteristics of social services for dependent people in these Communities. Cantabria exhibits a very low coverage index for Telecare services $^{24}$ (0.2, opposite to 0.78 for Spain). In this case, the shortage of mechanical devices for watching the dependent people may act as reinforcement for family care. Navarra is the region where the Home Care is more expensive ${ }^{25}$.

With respect to Ceuta, there are not any private or public day centers and shows the lowest coverage index for residential centers (1.46, in contrast with the Spanish average of $3.21^{26}$ ). It could be argued that there are other regions where the coverage index for Home Care is lower, but $70 \%$ of the time is devoted to home help and consequently, the carereceiver does not perceive that aid as specialized or skilled. On the other hand, Ceuta is the region with the lowest percentage of elder people living alone (14\%, opposite to $19.9 \%$ for Spain ${ }^{27}$ ) which may justify the prevalence of IC over FC.

Finally, the probability of receiving FC for old dependent is greater in Cataluña. Although the coverage index is lower than the national average (1.2 opposite to 1.8 ), $85 \%$ of Home Care time is devoted to personal care and only $15 \%$ to home help. In this sense, estimated coefficients might reveal how useful is perceived each type of care by the carereceiver.

\subsection{The hours equation}

The estimation results for the regression of caregiving hours (second step of the Bourguignon model) are shown in Table 7 . The variables $\mathrm{M}_{\mathrm{k}}(\mathrm{k}=1,2,3)$ are consistent estimators of the expected conditional residuals of the multinomial model. Each coefficient $\mathrm{M}_{\mathrm{k}}$ represents the covariance between the residual of least squares regression and the corresponding residual from the multinomial logit regression. The variable $\sigma_{1}$ represents the standard deviation of the regression error term. ${ }^{28}$

\footnotetext{
${ }^{24}$ Home Care and Telecare services depend upon local administration. Comparing the characteristics of these services across regions, we detect large disparities in both eligibility and generosity.

${ }^{25}$ The cost of Home Care service differs a lot across regions (the most expensive one is Navarra with $19.08 €$ /hour). Moreover, the co-payment percentage varies from $0 \%$ in Ceuta and Melilla (5\% in Andalucía and Murcia, 10\% in País Vasco,) to 20\% in Rioja.

${ }^{26}$ See Table G for coverage indexes of social services of dependent people.

${ }^{27}$ Censo de Población y Vivienda (Population and Dwelling Census, INE, 2001).

${ }^{28}$ We have also estimated the equation for the number of care hours by OLS, that is, without taking into account the correlation with the choice of the type of care [The results of these exercises are available upon request]. Comparing the results with those obtained in the bourginon model, we extract three important lessons. First, in the regression for FC, the number of caregiving years is not significant, but in
} 
The significance of the selectivity correction terms indicates that the appropriate estimation method for the hour equations is the model proposed by Bourguignon et al. (2004) rather than OLS. The multinomial logit selection model allow us not only to identify the direction of the bias related to the choice of a certain type of care, but also which choice among any two types of care is the cause of the bias.

Children $^{29}$, in some sense, put pressure on caregivers, because dependent people who co-reside with them receive less IC hours. In fact, we are being witness to the so-called "sandwich generation", that is, adult children who have to devote attention both to old parents and young children.

The sign of the estimated coefficients for the variable household income is quite interesting because the number of FC hours decreases for very low income and for the interval $1.953,29 €-3.906,58 €$. Regarding the provision of social services, Regional Administration is responsible for both the supply of social services and the determination of what requirements are needed to apply for one place. These requirements usually include a valuation of the degree of disability, the availability of informal care ant the financial situation of the applicant (Casado and López Casanovas, 2001; Casado, 2005). So high income households are, most likely, excluded from these services. But the only plausible explanation for low income households is information illiteracy about the offer of public services.

With respect to illnesses, we observe that mental illness, dementia, stroke and multiple sclerosis increase the number of IC hours. However, suffering arthritis decreases the number of IC. This may be because Alzheimer, multiple sclerosis and other types of dementia are degenerative and patients who have suffered a stroke need special care if they want to prevent a lethal repetition. But arthritis is a painful illness, that limits the ability for climbing stairs, maintaining body positions, walking, and do houseworking, but it does not provokes a shortfall of mental faculties.

the selection model there is an increase in the demand for FC hours during the first year of care and after the eighth year. It seems that at the onset of the disability or when the diagnosis is known, some people decide to look for FC. On the other side, for the case of chronic diseases, FC is requested to avoid institutionalisation. Second, some variables become insignificant when we do not control for selection bias. For example, in the regression for IC, this is the case of multiple sclerosis, disability for remembering/executing, number of $\mathrm{PADL}=2$ and the coverage index for telecare services are significant. In the regression for FIC, this is also the case for the number of adults living in the household, the number of PADL $=2$ and the coverage index for private residential homes. Third, in the regression for FC and FIC without controlling selection bias, lower income households demand less caregiving hours. However, in the multinomial logit selection model lower income intervals are not significant. Actually, low household income is a significant variable in the logistic model for the choice of care. Then, when we do not control selection bias we misinterpret the effect of income. Low income households tend to choose IC instead of FC or FIC. But, once the selection has been made, this variable is irrelevant for the number of hours demanded.

${ }^{29}$ This variable was not significant in the estimation of the hours equation by OLS (available upon request). 
Table B synthesises the interpretation of the selection bias correction terms shown in Table 7 of the Appendix. The number of the selection bias term corresponds to the alternative of care $(0=$ no care; $1=$ FC; $2=$ IC; $3=$ FIC $)$. We have found evidence in favour of the Complementary and Task Specific Model and against the Substitution Model. This conclusion should be taken with enthusiasm by policy makers because confirms that services for dependent people provided by the public sector are not going to substitute informal caregiver's support. Instead, formal care is going to share caregiving tasks with the family (Home Care, Day Centres), alleviate caregiver's burden (Respite services) or provide technological devices (Telecare).

Table B. Interpretation of the Bias Correction Terms of Bourguignon Model. All Sample

\begin{tabular}{|l|l|l|}
\hline \multicolumn{1}{|c|}{ Equation } & \multicolumn{1}{|c|}{ Interpretation } & \multicolumn{1}{|c|}{ Evidence in favour/against } \\
\hline M1 $>0$ in IC equation & $\begin{array}{l}\text { Individuals with IC receive more caregiving } \\
\text { hours compared to individuals taken at random, } \\
\text { due to the allocation of people with less } \\
\text { disabilities out of IC and into FC }\end{array}$ & Against Substitution Model \\
\hline M3<0 in IC equation & $\begin{array}{l}\text { Less caregiving hours of individuals with IC } \Rightarrow \\
\text { people with more disabilities out of IC and into } \\
\text { FIC }\end{array}$ & $\begin{array}{l}\text { In favour of Complementary and } \\
\text { Task Specific Model }\end{array}$ \\
\hline $\begin{array}{l}\text { M0 }>0 \text {, M1 }>0 \text { and M2 }>0 \\
\text { in FIC equation }\end{array}$ & $\begin{array}{l}\text { More caregiving hours of individuals with FIC } \\
\text { into No No Care, FC, IC. }\end{array}$ & $\begin{array}{l}\text { In favour of Complementary and } \\
\text { Task Specific Model }\end{array}$ \\
\hline
\end{tabular}

\subsection{Hours equation by age and gender}

Figure 9 shows the distribution of the number of caregiving hours by age and gender. Men subsample attains the highest percentage for more than 60 hours per week, followed by the sample of older individuals. By contrast, young people and women show the highest frequency for less than 7 hours per week. For the four subsamples, the intervals 30-40 and 40-60 hours per week show a deep decrease, which denotes not a monotone progression in the number of caregiving hours. 


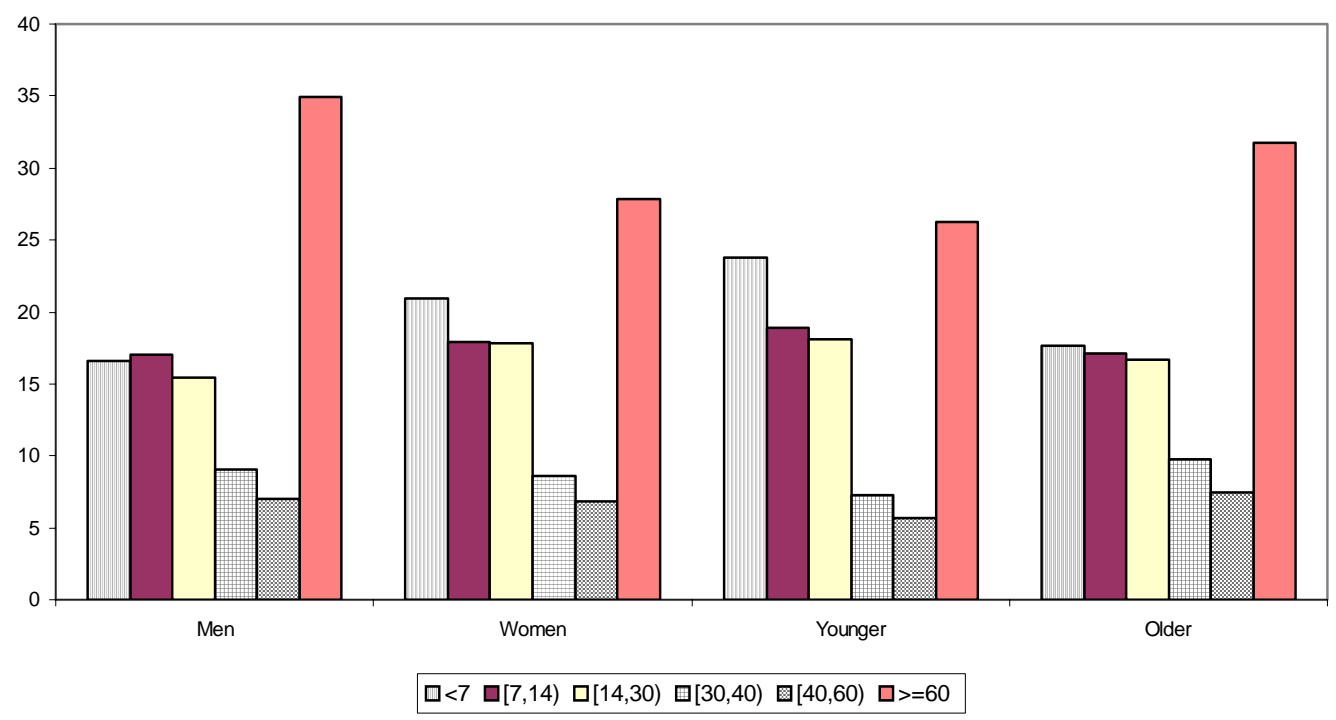

Figure 9. Distribution of the number of weekly caregiving hours by age and gender. Comparison Men and Women

Table 8 shows the results for the second step hour regressions by gender. First of all, none of the selectivity terms $\left(\mathrm{M}_{\mathrm{k}}, \mathrm{k}=1,2,3\right)$ are significant in the male regressions for $\mathrm{FC}$ and FIC. It appears that in these cases the choice of the type of care and the number of caregiving hours are independent variables. In fact, the goodness of fit for the male FC regression is very poor because from the sample of 562 observations who receive FC, only 98 are male.

As stated, Table 8 also reports the estimation of the second step of the Bourguignon model for women. Neither of the $M_{k}$ terms is significant for the FC hours equation, which means that the choice of formal care and the number of caregiving hours are independent decisions and therefore OLS estimation performs better.

We observe that age is not significant in the regression of IC for the subsample of men (whereas it is significant for the whole sample and the subsample of women). That is, for male, it is easier to receive IC independently of the age of the carereceiver. By contrast, for women, oldest age intervals are significant. On the other hand, widowed or divorced males tend to receive less IC hours, while only divorced women receive less IC hours (with a smaller coefficient compared to men). This indicates that having a couple practically guarantees the reception of IC hours, but dependent wives do not trust on their husbands as primary caregivers. Moreover, the number of co-resident adults is not significant for male but it is very significant for women (mainly daughters or daughters-in-law who behave as caregivers).

Suffering dementia, mental illness or having stayed at hospital increases the number of IC hours for both genders, although coefficients are always higher for men.

Comparison young and old 
Table 9 shows the estimation of the second step (hours equation) of the Bourguignon model by age groups: young dependent (40-69) and older dependent (70+). For young dependent, we find that for each equation at least one term $\mathrm{M}_{\mathrm{k}}$ is significant which indicates that the estimations by OLS are biased (Available upon request). In fact, if we compare the coefficients estimated for the FC hours equation by the BM and by OLS, there exist great disparities. We observe that suffering mental illness or muscular sclerosis decrease the number of FC hours and at the same time increase the number of FIC and IC hours (Compensatory or Complementary Model).

Having changed house, suffering muscular dystrophy or cerebral palsy increases the number of FC hours and having an impairment certificate increases both the number of FC and FIC hours. For muscular diseases, the availability of wheelchairs, crutches, kitchen accessories, devices for climbing stairs or bath adaptations combined with the surveillance of an employee or informal caregiver (in cases of very severe disabilities) may lengthen the independence of the individual.

With respect to the estimation of the hours equation for the subsample of old dependent people (70-99 years) (also reported in Table 9) we appreciate that none of the variables $M_{k}$ is significant for the FC hours equation, that is, in this case the estimation by least squares is preferred to the Bourguignon model.

As we have commented before, caregiver's sex is a capital question when determining the propensity to receive informal care. The estimations confirm that old-male dependent people also tend to receive more IC hours independently of marital status.

Suffering arthritis decreases the number of IC hours. This fact could seem surprising at first sight, because according to official statistics, arthritis is much more prevalent among women, but as we have seen previously women live longer and more women live alone ${ }^{30}$, and if they are married, as disability increases among married men, wives largely assume the increased care needs even when these women were themselves disabled.

If we compare the results for the subsample of young and old dependent people, we observe that the number of days stayed at hospital increases the number of IC hours for the subsample of old dependent, but it also decreases the number of FC hours for the subsample of young dependent. Sometimes, an acute event, that entails a hospital stay and gathering of relatives, implies the urgency of deciding the type of care. The initial decision may set up the course for subsequent care. Deciding which type of care is better requires knowing the benefits, risks and costs of the alternatives.

\footnotetext{
${ }^{30}$ From the sample of 7780 dependants, there are 1195 individuals who live alone (84\% women and $16 \%$ men). For the subsample of FC receivers, 251 individuals live alone (85.3\% women and $14.6 \%$ men).
} 
Having received a rehabilitation treatment has a different impact over younger and older dependent, because for the former, we observe that the number of FC and IC hours decreases, whereas for the latter ones this variable is not significant. This result may reflect that the possibilities of recovering are higher for younger people, and consequently if they experience an improvement in the ability for doing daily living activities, the demand of caregiving hours is reduced.

It is evident that the size of the municipality is related to the availability of social services for dependent people, but we observe that living in a municipality with 10.000-50.000 inhabitants increase the number of FC hours for young and decreases the number of FC hours for older people. The difference nature of the services demanded may be the answer to this disparity. Young people may be interested in rehabilitation treatment, whereas older ones may prefer day centres or home care.

With respect to the degree of severity, very severe disabilities increase the number of FC hours for young and the number of FIC hours for older dependent ${ }^{31}$. As we have commented before, young people prefer to maintain their autonomy and do not depend on relatives (perhaps because they do not want to disturb them or because their priority is to protect their intimacy).

Finally, for both subsamples the number of co-resident adults increase the number of FC, IC and FIC hours, indicating that the family may decide to provide more or less support to the dependent. Anyway, the highest coefficient corresponds to FC, so we could state that in most cases there is strong evidence against the Substitution Model.

Table C summarizes the interpretation of the selection bias terms for the four models we have estimated. Most cases point to the Complementary and Task-Specific Model, that is, IC does not decrease when dependent people start receiving FC, and at the same time, when caregiving demands go beyond IC abilities, more complex tasks are developed by formal caregivers. For the male subsample, as we have commented before the mainstream trend is to rely on IC, but in our opinion there may be an inefficient allocation of resources, that is, the carereceiver would be better receiving formal care alone or combined with informal one.

Table C. Interpretation of the Bias Correction Terms of Bourguignon Model.

\begin{tabular}{|l|l|l|}
\hline \multicolumn{1}{|c|}{ Equation } & \multicolumn{1}{|c|}{ Interpretation } & Evidence in favour/against \\
\hline MEN SUBSAMPLE & $\begin{array}{l}\text { Inefficient allocation of resources, because } \\
\text { although some male dependent people would } \\
\text { have been better with FC or FIC, remained } \\
\text { receiving only IC. }\end{array}$ & Inefficient allocation of resources \\
\hline M2<0 in IC equation &
\end{tabular}

\footnotetext{
31 These variables were not significant in the estimation by OLS of the hours equation (See Table 16 for old subsample and estimations are available upon request for young subsample).
} 


\begin{tabular}{|c|c|c|}
\hline \multicolumn{3}{|l|}{ WOMEN SUBSAMPLE } \\
\hline M1 $>0$ in IC equation & $\begin{array}{l}\text { More caregiving hours of individuals with IC } \Rightarrow \\
\text { people with less disabilities out of IC and into } \\
\text { FC }\end{array}$ & Against Substitution Model \\
\hline $\mathrm{M} 3<0$ in IC equation & $\begin{array}{l}\text { Less caregiving hours of individuals with IC } \Rightarrow \\
\text { people with more disabilities out of IC and into } \\
\text { FIC }\end{array}$ & $\begin{array}{l}\text { In favour of Complementary and } \\
\text { Task Specific Model }\end{array}$ \\
\hline $\begin{array}{l}\text { M0 }>0 \text { and } \mathrm{M} 1>0 \text { in FIC } \\
\text { eq. }\end{array}$ & $\begin{array}{l}\text { More caregiving hours of individuals with FIC } \\
\Rightarrow \text { people with less disabilities out of FIC and } \\
\text { into No care or FC. }\end{array}$ & $\begin{array}{l}\text { In favour of Complementary and } \\
\text { Task Specific Model }\end{array}$ \\
\hline \multicolumn{3}{|l|}{ YOUNG SUBSAMPLE } \\
\hline $\mathrm{M} 2>0$ in $\mathrm{FC}$ equation & $\begin{array}{l}\text { More caregiving hours of individuals with FC } \Rightarrow \\
\text { people with less disabilities out of FC and into } \\
\text { IC }\end{array}$ & In favour of Substitution Model \\
\hline $\mathrm{M} 1<0$ in IC equation & $\begin{array}{l}\text { Less caregiving hours individuals with IC } \Rightarrow \\
\text { people with more disabilities out of IC and into } \\
\text { FC. }\end{array}$ & In favour of Substitution Model \\
\hline $\mathrm{M} 1<0$ in FIC equation & $\begin{array}{l}\text { Less caregiving hours individuals with FIC } \Rightarrow \\
\text { people with more disabilities out of FIC and into } \\
\text { FC. }\end{array}$ & In favour of Substitution Model \\
\hline \multicolumn{3}{|l|}{ OLD SUBSAMPLE } \\
\hline M1 $>0$ in IC equation & $\begin{array}{l}\text { More caregiving hours of individual with IC } \Rightarrow \\
\text { people with less disabilities out of IC and into } \\
\text { FC. }\end{array}$ & Against Substitution Model \\
\hline M3 $<0$ in IC equation & $\begin{array}{l}\text { Less caregiving hours of individual with IC } \Rightarrow \\
\text { people with more disabilities out of IC and into } \\
\text { FIC }\end{array}$ & $\begin{array}{l}\text { In favour of Complementary and } \\
\text { Task Specific Model }\end{array}$ \\
\hline $\begin{array}{l}\text { M0 }>0, \text { M1 }>0 \text { and M2>0 } \\
\text { in FIC equation }\end{array}$ & $\begin{array}{l}\text { More caregiving hours of individuals with FIC } \\
\Rightarrow \text { people with less disabilities out of FIC and } \\
\text { into No care, FC, IC. }\end{array}$ & $\begin{array}{l}\text { In favour of Complementary and } \\
\text { Task Specific Model }\end{array}$ \\
\hline
\end{tabular}

\section{Conclusions}

One of the most important health policy issues that we face now is how to provide support to people with disabilities living in the community. Because of projected demographic shifts, families and policy makers will be confronted with an increase in the number of people who must cope with disabilities due to ageing or chronic disease.

Searching for a central tendency in long term care preferences is a worthwhile prelude to serious consideration of how to reshape policies and practices for dependent people. However, results from the multinomial logit for the choice of care point to the existence of differences by age and gender. Younger dependent seek care that let them to develop a life with enough degree of autonomy. By contrast, older dependent see their life as coming to a conclusion and ry to keep enough resources for the end of their lives or for their families. Perhaps is a societal problem, but the consequence could be that old dependent might be cut off from the insights of younger people of disabilities because do not know how to use the system of social protections. 
With respect to gender, it is worth to mention three relevant facts. First, women make up a greater number of dependent people because they tend to live longer than men. Second, disabled women may be more vulnerable to unmet needs because many of them live alone with limited resources ${ }^{32}$. Third, even married women may be more vulnerable because they tend to take care of their husbands even when they are partially disabled. In consequence, married women with disabilities may be more prone to unmet needs because of limited caregiving from their husbands and because they themselves must often remain as central caregiver in the family. On the grounds that many disabled women rely on children from support, (especially female children or daughters-in-law), the family burden and stress associated with caregiving for a disabled women should be the subject of a future study.

Regarding the provision of social services, the estimation results reveal large disparities among regions. In first place, the probability of receiving FC is lower in some communities. Second, the distribution of weights between home help and personal care in home care service is not homogeneous across regions. To our knowledge, if home care increased the fraction of time devoted to personal care, the service would be more efficient and would also generate a demand of skilled professionals (medical practitioners, nurses, physiotherapists, psychologists) ${ }^{33}$. The results of the analysis suggest the need to expand publicly funded home and community-based services, provide greater support for unpaid informal caregivers and more financing options for long-term services.

The Law of Personal Autonomy and Attention to Dependent People outlines a new dependency sector in which local authorities, regions and the state will have their own separate task identity. The state set ups the overall framework whereas local authorities will handle tasks directly targeted at the citizen. The Dependency Law provides a better basis for ensuring cohesive patient treatment across administrative borders as well as easy and simplified access to prevention, examination treatment and care of a high professional quality.

The Law reinforces the idea of prevention. This service is not only health check, but also an opportunity to meet individual needs that may be of importance for older people to stay independent. Prevention must comprise all aspects of an individual's well-being (functional ability, life content, possibilities of self-determination...). Research has documented the best functioning of the older population who receives preventive attention (Kendrick et al., 2001; Stuck et al., 2002). Moreover, older people visited by preventive staff are gaining confidence in public sector's ability to assist if specific needs should later arise, and thus it creates a sense of security in daily life.

\footnotetext{
${ }^{32} 72,90 \%$ of individuals with less than $390,6 €$ per month are women.

${ }^{33}$ According to "Libro Blanco de la Dependencia" and Herce et al. (2006), by 2010, the National Dependency System may generate as much as 262735 new jobs.
} 
From our point of view, more resources should be devoted to information. This approach requires the collection of standardized data to provide consumers with better information. Data on various types of long term care alternatives should be arrayed to show measures of quality (of care and of life), staffing qualifications and consumer satisfaction. Information could be provided through web sites, hospitals, outpatient clinics, health care practitioners, health departments...

Finally, the next step would be to develop a quality model for the National Dependency System in order to look for continuous clinical, professional and organizational quality improvements of patient treatment. Some quality standards should be defined in terms of what kind of help citizens are entitled if they need personal or practical help, rehabilitation or physical maintenance training. For each patient, it should be detailed the content, scope and rendering of the help, and set quality targets that could be used to assess efforts at least once a year. 


\section{$\underline{\text { References }}$}

1. Archbold, P., 1982. All consuming activity: the family as caregiver. Generations 7, 12-13.

2. Bass, D. M., Noelker L. S., 1987. The influence of family caregivers on elder's use of in-home services: and expanded conceptual framework. Journal of Health and Social Behavior 28, 184-196.

3. Bass, D., Noelker, L., 1989. Home care for elderly persons: linkages between formal and informal caregivers. Journal of Gerontology 44, S63-S70.

4. Bass, D., Noelker, L., 1994. Relationships between the frail elderly's informal and formal helpers. En E. Khana, D. Biegel, M. L. Wykle (eds.), Family caregiving across lifespan, 356-381. Albany, NY: State University of New York Press.

5. Bolin, K., B. Lindgren, P. Lundborg, 2008. Informal and Formal Care among single-living elderly in Europe. Health Economics 17, 393-409.

6. Bourguignon, F., Fournier, M., Gurgand, M., 2004. Selection bias corrections based on the multinomial logit model: Monte-Carlo comparisons. Department et Laboratoire d'Economie Théorique et Appliquée, Working Paper N. 2004-20.

7. Branch, L., Jette, A., Evashiwick, C., Polansky, M., Rowe, G., Diehr, P., 1981. Toward understanding elder's health service utilization. Journal of Community Health 7, 80-92.

8. Cantor, M., 1979. Neighbors and friends: and overlooked resource in the informal support system. Research on Aging 1, 434-463.

9. Cantor, M., 1991. Family and the community: changing roles in an aging society. The Gerontologist 31, 337-346.

10. Carmichael, F., Charles, S., 2003. Benefit payments, informal care and female labour supply. Applied Economic Letters 10, 411-415.

11. Casado, D., 2005. Envejecimiento y dependencia: un análisis económico de sus efectos sobre las finanzas públicas. Ph.D. Dissertation. Universitat Pompeu Fabra (mimeo).

12. Casado, D., López Casanovas, G., 2001. Vejez, dependencia y cuidados de larga duración: situación actual y perspectivas de futuro. Barcelona. Fundación “La Caixa”.

13. Censo de Población y Hogares. INE, 2001.

14. Chappell, N., 1991. In-group differences among elders living with friends and family other than spouse. Journal of Aging Studies 5, 61-76.

15. Chappell, N. L., Blandford, A, 1991. Informal and formal care: exploring the complementarity. Ageing and Society 11, 299-315.

16. Chi, P. S., Hsin, P. L., 1999. Medical utilization and health expenditures of the elderly in Taiwan. Journal of Family and Economic Issues 20, 251-270.

17. Christianson, J. B., 1988. The evaluation of the national long-term demonstration: the effect of channeling on informal caregiving. Health Services Research 23, 99-117.

18. Dahl, G. V., 2002. Mobility and the returns to education: testing a Roy model with multiple markets. Econometrica 70, 2367-2420.

19. Denton, M., 1997. The linkages between informal and formal care in the elderly. Canadian Journal on Aging 16, 30-50.

20. Dubin, J. A., McFadden, D. L., 1984. An econometric analysis of residential electric appliance holdings and consumption. Econometrica 52, 345-362.

21. Edelman, P., Hughes, S., 1990. The impact of community care on provision of informal care to homebound elderly persons. Journal of Gerontology 45, 74-84.

22. Elkan, R., Kendrick, D., Dewey, A., Hewitt, M., Robinson, J., Blair, M., Williams, D., Brummell, K., 2001. Effectiveness of home based support for older people: systematic review and meta-analysis. British Medical Journal 323, 1-8.

23. Ettner, S. L., 1995. The impact of parent care on female labor supply decisions. Demography 32, 6380.

24. Ettner, S. L., 1996. The opportunity costs of elder care. The Journal of Human Resources 31, 189205.

25. Fast, J. E., Williamson, D. L., Keating, N. C., 1999. The hidden costs of informal elder care. Journal of Family and Economic Issues 20, 301-326.

26. Federal Interagency Forum on Aging Related Statistics, 2000. Older Americans 2000: key indicators of well-being. Retrieved September 14, 2006. http:// www.agingstats.gov 
27. Fischer, L. R., Eustis, N. N., 1994. Care at home: family caregivers and home care workers. En E. Khana, D. Biegel, M. Wykle (eds.), Family caregiving across lifespan, 108-131. Albany, NY: State University of New York Press.

28. Glazer, N., 1990. The home as workshop: women as amateur nurses and medical care providers. Gender and Society 4, 479-499.

29. Greene, V., 1983. Substitution between formally and informally provided care for the impaired elderly in the community. Medical Care 21, 609-619.

30. Heckman, J., 1979. Sample selection bias as a specification error. Econometrica 47, 153-161.

31. Hirst, M. Carer distress: a prospective, population-based study. Social Science Medicine 61, 697-708.

32. Herce, J. A., Labeaga, J. M., Sosvilla Rivero, S., Ortega, C., 2006. Sistema Nacional de Dependencia. Evaluación de sus efectos sobre el empleo. IMSERSO.

33. Jiménez-Martín, S., Vilaplana, C., 2008. La calidad de los cuidadores en España. En S. JiménezMartín (Ed.), Aspectos económicos de la dependencia y del cuidado informal en España. Fundación Astrazeneca.

34. Keating, N. C., Fast, J. E., Connidis, I. A., Penning, M., Keefe, J., 1997. Bridging policy and research in eldercare. Special joint issue, Canadian Journal on Aging and Canadian Public Policy, 22-41.

35. Kemper, P., 1992. The use of formal and informal home care by the disabled elderly. Health Services Research 27, 421-454.

36. Langa, K. M., Chernew, M. E., Kabeto, M. U., Katz, S. J., 2001. The explosion in paid home care in 1990s: who received the additional services? Medical Care 39, 147-157.

37. Lee, L., 1983. Generalized econometric models with selectivity. Econometrica 51, 507-512.

38. Lee, G. R., Dwyer, J. W., Coward, R. T., 1993. Gender differences in parent care: demographic factors and same-gender preferences. Journal of Gerontology 48, S9-S16.

39. Libro Blanco de la Dependencia, 2004. Imserso

40. Litwak, E., 1985. Helping the elderly: the complementarity roles of informal networks and formal systems. New York: Guildford Press.

41. Liu, K., Manton, K. G., Aragon, C., 2000. Changes in home care use by disabled elderly persons: 1982-1984. Journal of Gerontology B: Psychological Scieces Social Sciences 55, S245-S253.

42. Mayall, B., 1993. Keeping children healthy; the intermediate domain. Social Science and Medicine 36, 77-83.

43. Moscovice, I., Davidson, G., McCaffrey, D., 1988. Substitution of formal and informal care for the community-based elderly. Medical Care 26, 971-981.

44. Norton, E. C., 2000. Long-term care. In A. J. Culyer, J. P. Newhouse (Eds.), Handbook of health economics. Vol 1B. Amsterdam: Elsevier Science.

45. Observatorio de personas mayores. Las personas mayores en España. IMSERSO, 2000.

46. Penning, M. J., Chappell, N. L., 1990. Self-care in relation to informal and formal care. Ageing and Society 10, 41-59.

47. Picone, G., Wilson, R. M., 1999. Medicare home health agency utilization, 1984-1994. Inquiry 36, 291-303.

48. Silverstain, M., Litwak, E., 1993. A task-specific typology of intergenerational family structure in later life. The Gerontologist 33, 258-264.

49. Stoller, E. P., 1989. Formal services and informal gerontology: the myth of service substitution. Journal of Applied Gerontology 8, 37-52.

50. Stoller, E. P., Earl, L. L., 1983. Help with activities of everyday life: sources of support for the noninstitutionalized elderly. The Gerontologist 23, 64-70.

51. Stoller, E. P., Pugliesi, K. L., 1991. Size and effectiveness of informal helping networks: a panel study of older people in the community. Journal of Health and Social Behavior 32, 180-191.

52. Stuck A. E, Egger, M., Hammer, A., Minder, C. E, Bek, J. C., 2002. Home visits to prevent nursing home admission and functional decline in elderly people. Systematic review and meta-regression. Journal of American Medical Association 287, 1022-1028.

53. Tennstedt, S. L., Crawford, S., L., McKinlay, J., 1993. Is family care on decline? A longitudinal investigation of the substitution of formal long-term care services for informal care. The Mildbank Quarterly 71, 601-625.

54. Tennstedt, S. L., McKinlay, J., Crawford, S. L., 1994. Unmeet need among disabled elders: A problem in access to community long care? Social Science Medicine 38, 915-924. 
55. Van Exel, N., van den Bos, G., van den Berg, B., Koopmanschap, M., 2004. What really matters: an inquiry into the relative importance of dimensions of care giving burden. Clinical Rehabilitation 18, 693-693.

56. Van Houtven, C. H., Norton, E. C., 2004. Informal care and health care use of older adults. Journal of Health Economics 23, 1159-1180.

57. Vittanen, T. K., 2007. Informal and formal care in Europe. Institute for the Study of Labor. IZA DP No. 2648.

58. Yang, Y., 2003. Can the strengths of AIC and BIC be shared? Department of Statistics. Iowa State University. http://www.stat.iastate.edu/preprint/articles/2003-10.pdf

59. White-Means, S., 1997. The demands of persons with disabilities for home health care and the economic consequences for informal caregivers. Social Science Quaterly 78, 955-972.

60. Zarit, S. H., Eggenbeen, D. J., 1995. Parent-child relationships in adulthood and old age. In M. H. Bornstein (Ed.), Handbook of parenting, Vol 1. Children and parenting. Mahwah, NJ: Erlbaum. 


\section{Appendix. Description of variables}

\section{A. Sociodemographic variables}

- Male : 1 if interviewed is male

- Age: five binary variables for the following intervals (40-49, 50-59, 60-69, 70-79, 80-89 and 90-99)

- Marital status: binary variables for "married/cohabiting", "single", "divorced/separated" and "widow"

- Number of adult household members

- Number of children: "less than 4 years old", "between 5 and 12 years" and "between 13 and 17 years"

- Level of education: binary variables for the categories "no studies", "elementary", "high school" and "college".

- Relation with economic activity: binary variables for "working”, "unemployed", "retired”, "receiving a contributive disability benefit", "non contributive disability benefit" and "houseworking".

- Monthly household-income: binary variables for nine intervals (<264.5; [264.5 - 390.6); [390.6 781.2); [781.2 - 1172); [1172 - 1562.6); [1562.6 - 1953.3); [1953.3 - 2344); [2344 - 3906.6); > 3906.5. There are $7.8 \%$ of the observations for which household income is missing.

- Size of municipality: binary variables for four population intervals $(<10.000$ inhabitants, 10.000 50.000, 50.000-500.000, >500.000).

- Autonomous Community: binary variable for each one of the Spanish Autonomous Communities.

\section{B. Health related variables}

- Illnesses and chronic pathologies: binary variables for the following diseases "mental illness", "muscular dystrophy”, "multiple sclerosis”, "stroke”, “cerebral palsy”, "dementia”, "arthritis” and "Parkinsonism".

- Change of house: 1 if the interviewed has changed of house because of a disability or deficiency (with the objective of living in an adapted household or receiving better medical attention)

- Rehabilitation treatment: 1 if the individual has already finished a rehabilitation treatment.

- Number of days stayed at hospital during last year.

C. Disabilities

- Seeing: receiving any image, global visual tasks, detailed visual tasks and other visual disabilities.

- Hearing: hearing any sound, hearing strong sounds and listening the speech.

- Communicating: communicating through speech, through alternative languages, through not sealed gestures and through conventional reading/writing.

- Executing/Remembering: recognizing people/objects, being orientated in space and time, remembering information and past episodes, dealing or executing simple orders or doing simple tasks, dealing or executing simple orders or doing complex tasks.

- Maintaining body postures: getting up and down, standing up and moving inside home.

- Using arms and hands: moving/transporting not very heavy objects, using utensils and tools, manipulating small objects with hands and fingers.

- Taking care of oneself: washing oneself, controlling physical needs, dressing and undressing, eating and drinking.

- Do houseworking: do the shopping, washing and ironing clothes, cleaning the house, looking after the well-being of the family.

- Relating: supporting relations of fondness with friends and relatives, meeting new friends, relations with workmates, employer and employees.

- Impairment certificate: this certificate is awarded to people with at least a 33\% reduction in the ability for performing daily living activities.

- Classification of the variable severity: without any difficulty, with moderate difficulty, with serious difficulty, cannot do the activity.

- Classification of the variable forecast: recoverable, recoverable with restrictions, stable without perspectives of improvement, can go worse, it is not possible to determine. 
Table 1. Public expenditure in ageing and long term care.

\begin{tabular}{|c|c|c|c|c|}
\hline & \multicolumn{3}{|c|}{ Ageing and long term care expenditure (2004) } & \multirow{2}{*}{$\begin{array}{c}\text { Dependency rate } \\
2007\end{array}$} \\
\hline & \% GDP & \% Health expenditure & \% Social Expenditure & \\
\hline Austria & 0.956 & 13.46 & 3.32 & 25.0 \\
\hline Belgium & 0.051 & 0.66 & 0.17 & 25.9 \\
\hline Denmark & 1731 & 28.38 & 5.75 & 23.2 \\
\hline Finland & 0.679 & 10.13 & 2.54 & 24.8 \\
\hline France & 0.324 & 3.68 & 1.03 & 24.9 \\
\hline Germany & 0.344 & 4.41 & 1.17 & 29.9 \\
\hline Greece & 0.097 & 1.49 & 0.40 & 27.6 \\
\hline Ireland & 0.225 & 3.26 & 1.24 & 16.2 \\
\hline Italy & 0.118 & 1.74 & 0.45 & 30.2 \\
\hline Luxembourg & - & - & - & 20.7 \\
\hline Netherlands & 0.874 & 10.79 & 3.10 & 21.5 \\
\hline Portugal & 0,253 & 1,29 & 2.82 & 25.6 \\
\hline Spain & 0.316 & 4.94 & 1.52 & 24.2 \\
\hline Sweeden & 2.492 & 33.23 & 7.79 & 26.4 \\
\hline United Kingdom & 1.046 & 12.91 & 3.90 & 24.1 \\
\hline EU-15 & 0.545 & 7.08 & 1.96 & - \\
\hline Bulgaria & 0.035 & 0.78 & 0.22 & 24.9 \\
\hline Cyprus & 0.002 & 0.04 & 0.01 & 17.6 \\
\hline Czech Republic & 0.33 & 5.08 & 1.73 & 20.2 \\
\hline Estonia & 0.083 & 2.13 & 0.66 & 25.1 \\
\hline Hungary & 0.381 & 5.95 & 1.74 & 23.2 \\
\hline Latvia & 0.144 & 3.68 & 0.92 & 24.8 \\
\hline Lithuania & 0.149 & 3.82 & 1.13 & 22.7 \\
\hline Malta & 0.585 & 12.19 & 3.20 & 19.8 \\
\hline Poland & 0.313 & 8.24 & 1.60 & 19.0 \\
\hline Romania & 0.012 & 0.24 & 0.08 & 21.3 \\
\hline Slovakia & 0.204 & 4.25 & 1.21 & 16.5 \\
\hline Slovenia & 0.186 & 2.51 & 0.79 & 22.7 \\
\hline UE-25 & 0.533 & 7.11 & 1.95 & 25.3 \\
\hline UE-27 & 0.528 & 7.04 & 1.94 & 25.2 \\
\hline
\end{tabular}

Source: Eurostat (Population and Social Conditions. Data for Portugal corresponds to 2004..

Dependency ratio: number of people 65 and older divided by total active population (15-64 years old)

Table 2. Descriptive Statistics by type of care received

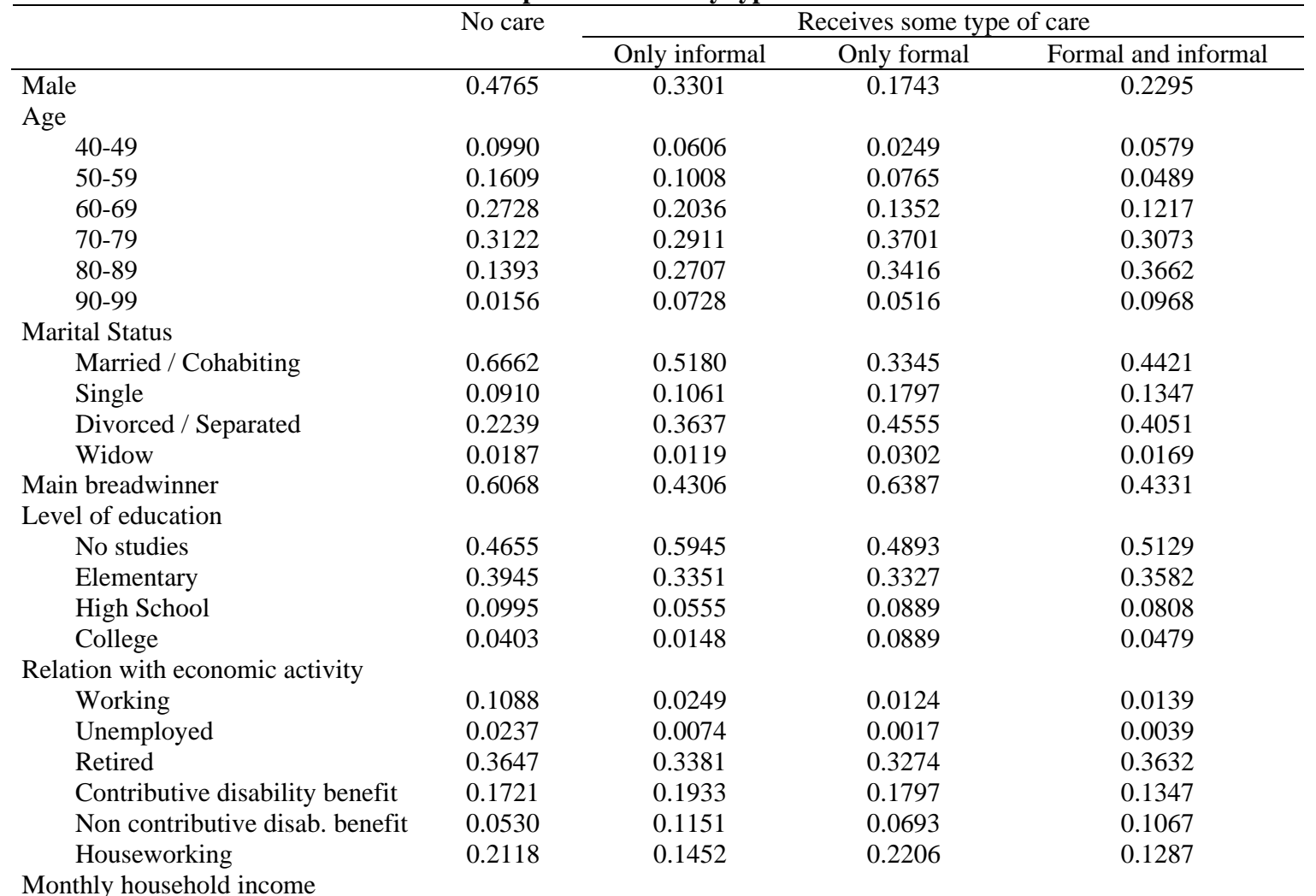




\begin{tabular}{|c|c|c|c|c|}
\hline$<264,5 €$ & 0.0195 & 0.0209 & 0.0231 & 0.0199 \\
\hline $264,5-390,6 €$ & 0.1503 & 0.1349 & 0.2526 & 0.1846 \\
\hline $390,6-781,2 €$ & 0.4032 & 0.3938 & 0.3683 & 0.3323 \\
\hline $781,2-1.171,97 €$ & 0.1929 & 0.2054 & 0.1476 & 0.1536 \\
\hline $1.171,97-1.562,63 €$ & 0.0863 & 0.0982 & 0.0569 & 0.0938 \\
\hline $1.562,63-1.953,29 €$ & 0.0359 & 0.0442 & 0.0177 & 0.0568 \\
\hline $1.953 .29-2.343,95 €$ & 0.0169 & 0.0141 & 0.0195 & 0.0269 \\
\hline $2.343,95-3.906,58 €$ & 0.0137 & 0.0115 & 0.0177 & 0.0329 \\
\hline$>3.906,58 €$ & 0.0024 & 0.0012 & 0.0035 & 0.0099 \\
\hline mber of adults & 2.7460 & 3.0518 & 1.8576 & 2.4351 \\
\hline \multicolumn{5}{|l|}{ mber of children } \\
\hline Less than 4 years & 0.0223 & 0.0247 & 0.0017 & 0.0109 \\
\hline Between 5 and 12 years & 0.0752 & 0.0841 & 0.0160 & 0.0349 \\
\hline Between 13 and 17 years & 0.1055 & 0.1113 & 0.0160 & 0.0658 \\
\hline \multicolumn{5}{|l|}{ e of municipality } \\
\hline$<10.000$ inhabitants & 0.3057 & 0.3230 & 0.2758 & 0.2395 \\
\hline $10.000-50.000$ & 0.2233 & 0.2549 & 0.2046 & 0.2035 \\
\hline $50.000-500.000$ & 0.3672 & 0.3342 & 0.3914 & 0.4371 \\
\hline$>500.000$ & 0.1037 & 0.0876 & 0.1281 & 0.1197 \\
\hline \multicolumn{5}{|l|}{ lesses } \\
\hline Mental illness & 0.0216 & 0.0559 & 0.0320 & 0.2588 \\
\hline Arthritis & 0.2170 & 0.3021 & 0.3576 & 0.2854 \\
\hline Muscular dystrophy & 0.0284 & 0.0611 & 0.0658 & 0.0188 \\
\hline Multiple sclersosis & 0.0122 & 0.0199 & 0.0195 & 0.0289 \\
\hline Stroke & 0.0737 & 0.1077 & 0.0943 & 0.1087 \\
\hline Cerebral palsy & 0.0276 & 0.0900 & 0.0516 & 0.1217 \\
\hline Dementia & 0.0104 & 0.0822 & 0.0516 & 0.1327 \\
\hline Parkinsonism & 0.0146 & 0.0398 & 0.0355 & 0.0658 \\
\hline ange of house due to disability & 0.0259 & 0.1077 & 0.0818 & 0.1217 \\
\hline habilitation treatment & 0.1184 & 0.1819 & 0.2241 & 0.2365 \\
\hline pairment certificate & 0.1617 & 0.1933 & 0.1743 & 0.2125 \\
\hline mber days at hospital last year & 1.4904 & 3.7968 & 3.7419 & 5.4371 \\
\hline mber of disabilities & 3.1469 & 9.6819 & 8.3505 & 12.6147 \\
\hline
\end{tabular}


Table 3. Descriptive Statistics (continuation)

\begin{tabular}{|c|c|c|c|c|}
\hline & \multirow[t]{2}{*}{ No care } & \multicolumn{3}{|c|}{ Receives some type of care } \\
\hline & & Only informal & Only formal & Formal and informal \\
\hline \multicolumn{5}{|l|}{ Disability for: } \\
\hline Seeing & 0.3169 & 0.2712 & 0.2971 & 0.3013 \\
\hline Hearing & 0.3634 & 0.1985 & 0.1975 & 0.2195 \\
\hline Communicating & 0.0577 & 0.1970 & 0.1281 & 0.2964 \\
\hline Executing / Remembering & 0.0692 & 0.2240 & 0.1850 & 0.3043 \\
\hline Maintaining body postures & 0.2432 & 0.5183 & 0.4911 & 0.6357 \\
\hline Using hands and fingers & 0.2106 & 0.4567 & 0.3932 & 0.5562 \\
\hline Moving outside home & 0.4051 & 0.8605 & 0.7722 & 0.8952 \\
\hline Taking care of oneself & 0.0417 & 0.4644 & 0.2829 & 0.5908 \\
\hline Houseworking & 0.1677 & 0.7881 & 0.9181 & 0.9381 \\
\hline Relating to other people & 0.0733 & 0.2268 & 0.1957 & 0.3043 \\
\hline Number of disabilities for PADL & 0.5040 & 2.1476 & 1.6423 & 3.0708 \\
\hline $\mathrm{PADL}=2$ & 0.0768 & 0.1359 & 0.1227 & 0.1037 \\
\hline $\mathrm{PADL}=3$ & 0.0432 & 0.1219 & 0.1032 & 0.1217 \\
\hline PADL $>=4$ & 0.0182 & 0.2446 & 0.1690 & 0.4071 \\
\hline Number of disabilities for IADL & 1.4346 & 5.6134 & 4.9750 & 6.7754 \\
\hline $\mathrm{IADL}=2$ & 0.1481 & 0.1048 & 0.1120 & 0.0528 \\
\hline $\mathrm{IADL}=3$ & 0.1057 & 0.1140 & 0.1476 & 0.0708 \\
\hline IADL $>=4$ & 0.1155 & 0.7089 & 0.6476 & 0.8522 \\
\hline \multicolumn{5}{|l|}{ Degree of severity } \\
\hline No severe & 0.0287 & 0.0476 & 0.0569 & 0.0469 \\
\hline Moderate severity & 0.8751 & 0.9895 & 0.9786 & 0.9940 \\
\hline Very severe & 0.5791 & 0.9565 & 0.9306 & 0.9860 \\
\hline Can not do the activity & 0.3638 & 0.8812 & 0.8185 & 0.9510 \\
\hline \multicolumn{5}{|l|}{ Prognosis } \\
\hline Recoverable & 0.0722 & 0.0157 & 0.0088 & 0.0139 \\
\hline Recoverable with restrictions & 0.0509 & 0.0553 & 0.0747 & 0.0508 \\
\hline Stable & 0.4399 & 0.4803 & 0.4466 & 0.4990 \\
\hline Can go worse & 0.5291 & 0.7102 & 0.7117 & 0.7425 \\
\hline Do not know & 0.0829 & 0.0928 & 0.0943 & 0.0998 \\
\hline $\mathrm{N}$ & 9662 & 6216 & 562 & 1002 \\
\hline
\end{tabular}


Table 4. Bourguignon Model. First step multinomial model. All sample. Marginal effects

\begin{tabular}{|c|c|c|c|c|c|c|}
\hline & \multicolumn{2}{|c|}{ Formal Care } & \multicolumn{2}{|c|}{ Informal Care } & \multicolumn{2}{|c|}{ Formal \& Informal } \\
\hline & $\mathrm{dy} / \mathrm{dx}$ & p-value & $\mathrm{dy} / \mathrm{dx}$ & p-value & $\mathrm{dy} / \mathrm{dx}$ & p-value \\
\hline Base Case & 0.02460 & & 0.27816 & & 0.01389 & \\
\hline Male & -0.03232 & $* * *$ & -0.01564 & $* *$ & -0.00874 & $* * *$ \\
\hline 50-59 & 0.02041 & $* *$ & 0.00796 & & -0.00602 & $* *$ \\
\hline $60-69$ & 0.01396 & $*$ & 0.03303 & $*$ & -0.00345 & \\
\hline $70-79$ & 0.04272 & $* * *$ & 0.07696 & $* * *$ & 0.00592 & $* * *$ \\
\hline $80-99$ & 0.02078 & $* * *$ & 0.13711 & $* * *$ & 0.00896 & $* * *$ \\
\hline Married & -0.02403 & $* * *$ & -0.00460 & & -0.00251 & \\
\hline Widowed & -0.01171 & $* * *$ & 0.03443 & & -0.00433 & $* *$ \\
\hline Divorced & 0.00093 & & -0.03851 & & -0.00033 & \\
\hline Main Breadwinner & 0.00198 & & -0.06441 & $* * *$ & -0.00804 & $* * *$ \\
\hline \multicolumn{7}{|l|}{ Level of education } \\
\hline Elementary & 0.00377 & & 0.00383 & & 0.00220 & $* *$ \\
\hline High School & 0.01939 & $* * *$ & -0.03758 & $*$ & 0.00511 & \\
\hline College & 0.07376 & $* * *$ & -0.10577 & $* * *$ & 0.00948 & $* *$ \\
\hline \multicolumn{7}{|l|}{ Relation with economic activity } \\
\hline Retired & -0.00559 & & -0.01606 & & -0.00100 & \\
\hline Contributive disability benefit & 0.00507 & & 0.01339 & & -0.00192 & \\
\hline Non contrib. disability benefit & 0.00099 & & 0.06129 & $* * *$ & 0.00023 & \\
\hline Houseworking & 0.00980 & $* *$ & -0.02746 & $*$ & -0.00214 & \\
\hline Number of children $13-17$ years & -0.00489 & & -0.00598 & & 0.00563 & $* *$ \\
\hline \multicolumn{7}{|l|}{ Monthly household income } \\
\hline$<390,6 €$ & -0.01526 & $* * *$ & 0.00758 & & -0.00383 & \\
\hline $390,6 €-1.171,97 €$ & -0.01412 & $* *$ & 0.02198 & & -0.00658 & $* *$ \\
\hline $1.171,97 €-1.953,29 €$ & -0.00906 & & 0.03840 & * & 0.00406 & $*$ \\
\hline $1.953,29 €-3.906,58 €$ & 0.02302 & $*$ & -0.06662 & $*$ & 0.01531 & $* * *$ \\
\hline$>3.906,58 €$ & 0.04914 & & -0.15790 & & 0.04800 & $* *$ \\
\hline Number household adults & -0.01621 & $* * *$ & 0.02327 & $* * *$ & -0.00682 & $* * *$ \\
\hline \multicolumn{7}{|l|}{ Size of municipality } \\
\hline$<10.000$ & 0.00091 & & -0.01386 & & -0.00647 & $* * *$ \\
\hline $10.000-50.000$ & 0.00028 & & 0.01137 & & -0.00469 & $* *$ \\
\hline $50.000-500.000$ & 0.00354 & & -0.01097 & & -0.00148 & \\
\hline \multicolumn{7}{|l|}{ Illnesses } \\
\hline Mental illness & -0.00372 & & 0.12048 & $* * *$ & 0.00668 & $* * *$ \\
\hline Arthritis & 0.00365 & $*$ & 0.02438 & $* *$ & -0.00062 & \\
\hline Muscular distrophy & 0.00818 & & -0.00326 & & -0.00306 & \\
\hline Multiple scelerosis & -0.00429 & & -0.02800 & & 0.00014 & \\
\hline Stroke & 0.00222 & & 0.03993 & $* * *$ & 0.00306 & $* *$ \\
\hline Cerebral palsy & -0.00324 & & 0.09157 & $* * *$ & 0.00567 & $* * *$ \\
\hline Dementia & -0.00161 & & 0.16347 & $* * *$ & 0.00776 & $* * *$ \\
\hline Parkinsonism & 0.00213 & & -0.01665 & & 0.00366 & \\
\hline Change of house & 0.01142 & $* * *$ & 0.08710 & $* * *$ & 0.00478 & $* * *$ \\
\hline Rehabilitation treatment & 0.01016 & $* * *$ & 0.02409 & $* *$ & 0.00810 & $* * *$ \\
\hline Impairment certificate & -0.00086 & & -0.01603 & & -0.00002 & \\
\hline Number of days at hospital & 0.00014 & $* *$ & 0.00105 & $* * *$ & 0.00010 & $* * *$ \\
\hline Number of disabilities & 0.00339 & & -0.02724 & $* * *$ & -0.00031 & \\
\hline \multicolumn{7}{|l|}{ Disabilities for: } \\
\hline Seeing & -0.01034 & $* * *$ & -0.01520 & & -0.00241 & $* *$ \\
\hline Hearing & -0.01467 & $* * *$ & -0.05147 & $* * *$ & -0.00368 & $* * *$ \\
\hline Communicating & -0.00906 & & 0.09105 & $* * *$ & 0.00580 & $* * *$ \\
\hline Remembering/Executing & -0.01140 & $* *$ & -0.06560 & $* *$ & -0.00396 & $*$ \\
\hline Relating & -0.00342 & & 0.00308 & & -0.00393 & \\
\hline Number of PADL & -0.00476 & & 0.03826 & $* * *$ & 0.00253 & $* * *$ \\
\hline PADL = 2 & -0.00279 & & -0.01047 & & -0.00342 & $*$ \\
\hline PADL = 3 & -0.00371 & & -0.04156 & & -0.00400 & $*$ \\
\hline PADL > = 4 & 0.01326 & & 0.05381 & & 0.00099 & \\
\hline Number of IADL & 0.00129 & $* * *$ & 0.09022 & $* * *$ & 0.00392 & $* * *$ \\
\hline IADL = 2 & 0.01416 & $* * *$ & 0.11086 & $* * *$ & 0.01265 & $* * *$ \\
\hline IADL =3 & 0.03254 & $* * *$ & 0.10445 & $* * *$ & 0.01759 & $* * *$ \\
\hline IADL >=4 & 0.03547 & $* * *$ & 0.16339 & $* * *$ & 0.02358 & $* * *$ \\
\hline \multicolumn{7}{|l|}{ Severity } \\
\hline No severe Moderate severe & -0.00654 & & 0.11521 & $* * *$ & -0.00543 & \\
\hline Very severe & 0.00356 & & 0.12108 & $* * *$ & 0.00656 & $* *$ \\
\hline Can not do the activity & -0.00460 & & 0.04962 & $* * *$ & 0.00427 & $*$ \\
\hline
\end{tabular}




\begin{tabular}{|c|c|c|c|c|c|c|}
\hline Recoverable (with restrict) & 0.01267 & $* * *$ & 0.07372 & $* * *$ & 0.00369 & $* *$ \\
\hline Stable & 0.00736 & $* * *$ & 0.07778 & $* * *$ & 0.00492 & $* * *$ \\
\hline Can go worse & 0.00910 & $* * *$ & 0.10059 & $* * *$ & 0.00637 & $* * *$ \\
\hline Do not know & 0.00645 & * & 0.03984 & $* *$ & 0.00276 & * \\
\hline \multicolumn{7}{|l|}{ utonomous Communities } \\
\hline Andalucia & -0.00665 & & 0.09909 & $*$ & -0.00456 & \\
\hline Aragón & -0.00097 & & 0.06374 & & -0.00107 & \\
\hline Asturias & -0.00525 & & 0.07508 & & -0.00766 & \\
\hline Baleares & -0.00260 & & 0.02472 & & -0.00141 & \\
\hline Canarias & -0.01513 & * & -0.05280 & & -0.00571 & \\
\hline Cantabria & -0.01338 & & 0.14669 & $* *$ & -0.00538 & \\
\hline Catilla La Mancha & -0.00862 & & 0.04985 & & -0.00498 & \\
\hline Castilla León & -0.00763 & & 0.08569 & & -0.00373 & \\
\hline Cataluña & 0.00355 & & 0.04099 & & -0.00729 & \\
\hline Extremadura & 0.00071 & & 0.08560 & & 0.00769 & \\
\hline Galicia & -0.01086 & & 0.01240 & & -0.00878 & $* *$ \\
\hline Madrid & -0.00732 & & -0.04091 & & -0.00902 & $* *$ \\
\hline Murcia & -0.00838 & & 0.08330 & & -0.00649 & \\
\hline Navarra & -0.01171 & & 0.19032 & ** & 0.00769 & $*$ \\
\hline Rioja & -0.01367 & & -0.03557 & & -0.00467 & \\
\hline País Vasco & -0.01039 & & 0.03156 & & -0.00647 & \\
\hline C. Valenciana & -0.01422 & & 0.10208 & & -0.00527 & \\
\hline Ceuta & -0.00940 & & -0.03046 & & 0.00256 & \\
\hline & 562 & & $\begin{array}{r}6.216 \\
0.35\end{array}$ & & 1.002 & \\
\hline
\end{tabular}

Omitted category: No care. Omitted variables: age 40-49, no studies, active, missing value for household income, number of children less than 13 years old, single, size of municipality $>500.000$ inhabitants and Melilla. $\left(^{*} \mathrm{p}<0.10\right.$; $\left.\mathrm{p}<0.05 ;{ }^{* * *} \mathrm{p}<0.01\right)$. dy/dx= variation with respect to the base case.

Base Case: men, age 80-99, married, elementary education, retired, household income between 390,6 $€$ and 1.171,97

$€$ per month, one PADL and one IADL disabilities, living in Cataluña.

Table 5. Bourguignon Model. First step multinomial model by gender. Marginal effects

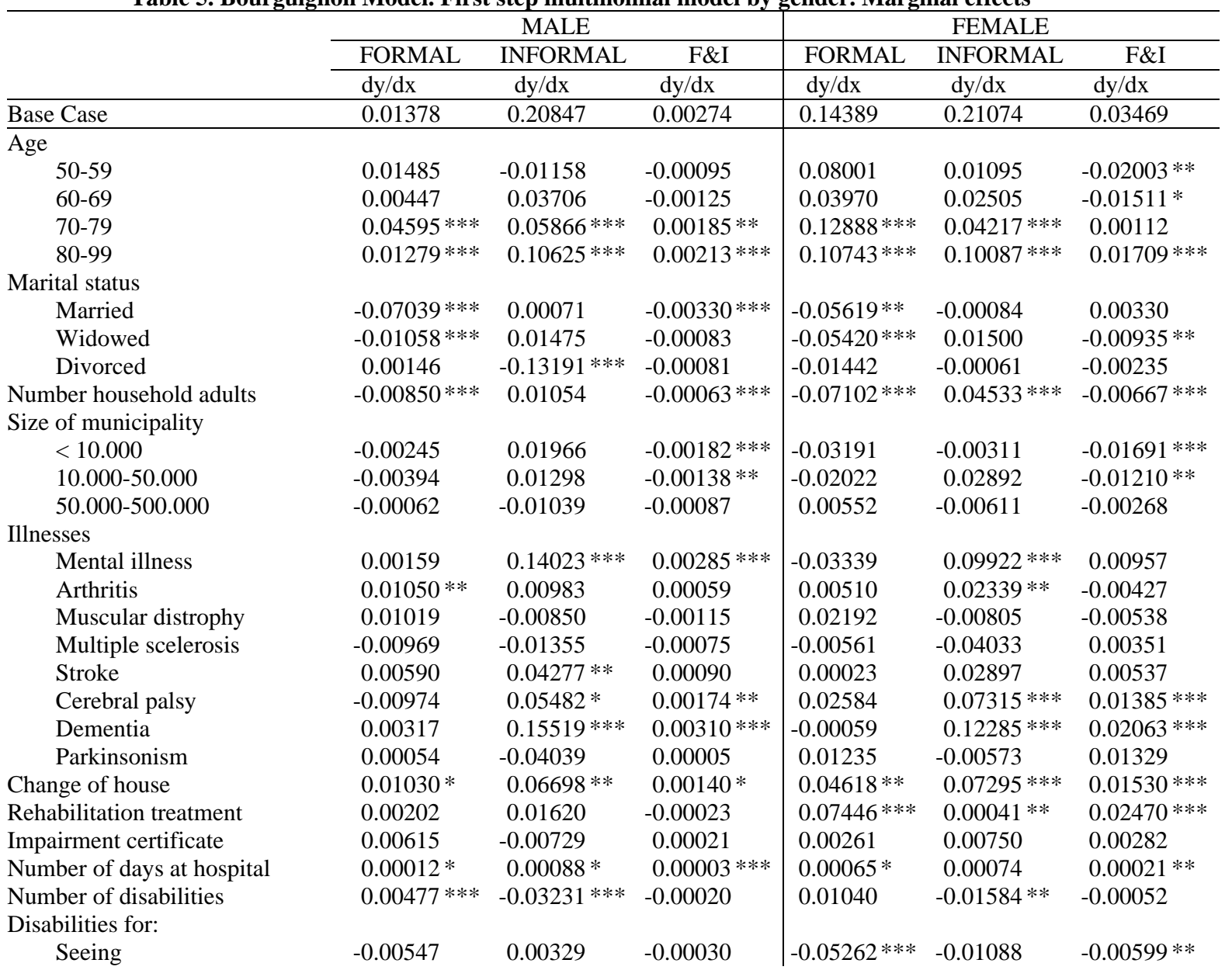




\begin{tabular}{|c|c|c|c|c|c|c|}
\hline Hearing & $-0.01198 * * *$ & $-0.06109 * * *$ & -0.00047 & $-0.07002 * * *$ & $-0.02125 * * *$ & $-0.00793 * * *$ \\
\hline Communicating & $-0.01303 * *$ & $0.14880 * * *$ & $0.00283 * * *$ & -0.02719 & 0.03464 & 0.00913 \\
\hline Remembering/Executing & $-0.01320 * *$ & -0.04692 & $-0.00133 *$ & -0.02020 & -0.02378 & -0.00354 \\
\hline Relating & 0.00348 & 0.05286 & $0.00219 *$ & -0.05304 & $-0.03936 *$ & $-0.01965 * * *$ \\
\hline Number of PADL & -0.00360 & $0.08137 * * *$ & $0.00112 * * *$ & -0.02227 & 0.00714 & 0.00487 \\
\hline $\mathrm{PADL}=2$ & -0.00022 & 0.00006 & $-0.00152 *$ & -0.01780 & -0.00839 & -0.00748 \\
\hline $\mathrm{PADL}=3$ & -0.00553 & $-0.08829 * *$ & -0.00114 & -0.01868 & 0.00053 & -0.00995 \\
\hline PADL $>=4$ & 0.00742 & 0.00213 & 0.00005 & 0.02409 & 0.02361 & -0.00469 \\
\hline Number of IADL & -0.00256 & $0.08094 * * *$ & $0.00079 * * *$ & $0.01817 * * *$ & $0.06658 * * *$ & $0.01039 * * *$ \\
\hline $\mathrm{IADL}=2$ & 0.01013 & $0.05248 * *$ & $0.00564 * *$ & $0.05691 * *$ & $0.09940 * * *$ & $0.01783 * *$ \\
\hline $\mathrm{IADL}=3$ & $0.03403 * *$ & 0.03279 & $0.00584 * *$ & $0.11925 * * *$ & $0.07512 * * *$ & $0.03161 * * *$ \\
\hline IADL $>=4$ & $0.03030 * *$ & $0.11467 * * *$ & $0.00679 * * *$ & $0.14140 * * *$ & $0.10403 * * *$ & $0.04615 * * *$ \\
\hline \multicolumn{7}{|l|}{ Severity } \\
\hline \multicolumn{7}{|l|}{ No severe/ Moderate } \\
\hline severe & -0.00489 & $0.10787 * * *$ & $0.00971 * * *$ & -0.03947 & $0.07896 * *$ & -0.02677 \\
\hline Very severe & 0.01791 & $0.10673 * * *$ & 0.00249 & 0.00004 & $0.08323 * * *$ & 0.01035 \\
\hline Can not do the activity & $0.01027 *$ & $0.07912 * * *$ & 0.00122 & -0.04082 & 0.02144 & 0.00704 \\
\hline \multicolumn{7}{|l|}{ Forecast } \\
\hline Recoverable (with restrict) & -0.00150 & $0.08224 * * *$ & 0.00057 & $0.07974 * * *$ & $0.02702 * * *$ & $0.00786 * *$ \\
\hline Stable & 0.00047 & $0.06090 * * *$ & $0.00096 * *$ & $0.04487 * * *$ & $0.05908 * * *$ & $0.01376 * * *$ \\
\hline Can go worse & -0.00047 & $0.08748 * * *$ & 0.00060 & $0.05535 * * *$ & $0.06918 * * *$ & $0.01745^{* * *}$ \\
\hline Do not know & -0.00499 & -0.00346 & 0.00025 & $0.05372 * * *$ & $0.03434 * * *$ & $0.00831 * *$ \\
\hline \multicolumn{7}{|l|}{ Autonomous Communities } \\
\hline Andalucia & -0.00490 & 0.03929 & -0.00240 & 0.06404 & -0.01087 & -0.00388 \\
\hline Aragón & -0.00472 & -0.00139 & -0.00091 & 0.15090 & -0.05083 & 0.00341 \\
\hline Asturias & 0.00824 & 0.05555 & -0.00098 & 0.04176 & -0.04910 & -0.01813 \\
\hline Baleares & -0.00263 & 0.08341 & -0.00086 & 0.06893 & -0.10176 & -0.00170 \\
\hline Canarias & -0.00991 & 0.01090 & -0.00101 & -0.03288 & $-0.12236 * * *$ & -0.01772 \\
\hline Cantabria & -0.00170 & 0.08637 & -0.00229 & -0.01818 & 0.01722 & 0.00019 \\
\hline Catilla La Mancha & -0.00831 & -0.03201 & -0.00204 & 0.06016 & -0.03072 & -0.00463 \\
\hline Castilla León & -0.00566 & -0.00016 & -0.00144 & 0.08666 & -0.02505 & -0.00164 \\
\hline Cataluña & -0.00322 & 0.02286 & -0.00254 & 0.08163 & -0.07718 & -0.00866 \\
\hline Extremadura & 0.00352 & 0.05381 & 0.00114 & 0.09106 & -0.04862 & 0.01973 \\
\hline Galicia & -0.00378 & -0.01489 & $-0.00248 *$ & 0.00969 & -0.06857 & -0.01738 \\
\hline Madrid & 0.00120 & 0.02896 & -0.00108 & 0.02248 & $-0.12115 * * *$ & $-0.02285 * *$ \\
\hline Murcia & -0.00128 & 0.09891 & -0.00140 & 0.00189 & -0.04036 & -0.01616 \\
\hline Navarra & -0.00645 & 0.12595 & 0.00229 & 0.06074 & 0.02353 & 0.04057 \\
\hline Rioja & -0.00428 & -0.07313 & -0.00138 & 0.13269 & -0.06432 & 0.01510 \\
\hline País Vasco & -0.00826 & -0.03963 & -0.00116 & 0.00972 & $-0.10404 * *$ & -0.00709 \\
\hline C. Valenciana & -0.00564 & -0.03236 & -0.00189 & 0.01683 & -0.04441 & -0.01157 \\
\hline Ceuta & -0.01569 & 0.01323 & -0.00313 & 0.00476 & -0.10399 & 0.01033 \\
\hline $\mathrm{N}$ & 98 & 2.052 & 230 & 464 & 4.164 & 772 \\
\hline & & 0.4075 & & & 0.3121 & \\
\hline Log Likelihood & & -3338.8633 & & & -7543.9634 & \\
\hline
\end{tabular}

Table 6. Bourguignon Model. First step multinomial model by age group. Marginal effects

\begin{tabular}{|c|c|c|c|c|c|c|}
\hline & \multicolumn{3}{|c|}{ YOUNG(40-69) } & \multicolumn{3}{|c|}{ OLDER $(70+)$} \\
\hline & FORMAL & INFORMAL & F\&I & INFORMAL & FORMAL & F\&I \\
\hline & $\mathrm{dy} / \mathrm{dx}$ & $\mathrm{dy} / \mathrm{dx}$ & $\mathrm{dy} / \mathrm{dx}$ & $\mathrm{dy} / \mathrm{dx}$ & $\mathrm{dy} / \mathrm{dx}$ & $\mathrm{dy} / \mathrm{dx}$ \\
\hline Base Case & 0.00262 & 0.13512 & 0.00071 & 0.04121 & 0.29101 & 0.01651 \\
\hline Male & $-0.00660 * * *$ & $-0.06300 * * *$ & $-0.00267 * * *$ & $-0.03696 * * *$ & $-0.02914 * * *$ & $-0.01164 * * *$ \\
\hline \multicolumn{7}{|c|}{ - } \\
\hline Married & $-0.00426 * * *$ & -0.01015 & $-0.00039 *$ & $-0.04526 * * *$ & -0.00312 & -0.00144 \\
\hline Widowed & $-0.00119 *$ & -0.02431 & $-0.00059 * * *$ & $-0.02243 * * *$ & 0.03768 & -0.00240 \\
\hline Divorced & 0.00021 & -0.02690 & -0.00022 & -0.01233 & $-0.15457 * *$ & -0.00188 \\
\hline Number household adults & $-0.00094 * * *$ & $0.00911 * * *$ & $-0.00015 * * *$ & $-0.02711 * * *$ & $0.04130 * * *$ & $-0.00387 * * *$ \\
\hline$<10.000$ & -0.00055 & $0.03626 *$ & -0.00012 & -0.01016 & $-0.04377 * *$ & $-0.01029 * * *$ \\
\hline $10.000-50.000$ & -0.00099 & $0.03467 *$ & 0.00001 & -0.00492 & -0.00350 & $-0.00816 * * *$ \\
\hline $50.000-500.000$ & 0.00058 & 0.01965 & 0.00035 & -0.00222 & -0.03775 & $-0.00443 * *$ \\
\hline \multicolumn{7}{|l|}{ Illnesses } \\
\hline Mental illness & 0.00063 & $0.09547 * * *$ & $0.00056 * *$ & -0.00551 & 0.06594 & 0.00078 \\
\hline Arthritis & -0.00015 & -0.00352 & -0.00021 & $0.00768 * *$ & $0.04632 * * *$ & 0.00060 \\
\hline
\end{tabular}




\begin{tabular}{|c|c|c|c|c|c|c|}
\hline Muscular distrophy & 0.00081 & -0.01669 & -0.00006 & 0.01126 & 0.03133 & -0.00359 \\
\hline Multiple scelerosis & 0.00128 & -0.01705 & 0.00014 & -0.01916 & -0.03823 & 0.00055 \\
\hline Stroke & -0.00018 & $0.03246 * *$ & 0.00023 & 0.00411 & $0.04016 * *$ & 0.00276 \\
\hline Cerebral palsy & -0.00081 & 0.01413 & 0.00030 & -0.00102 & $0.13494 * * *$ & $0.00790 * * *$ \\
\hline Dementia & $0.00970 * *$ & $0.08990 *$ & 0.00075 & -0.00605 & $0.19275 * * *$ & $0.01448 * * *$ \\
\hline Parkinsonism & -0.00122 & $0.07390 *$ & $0.00100 * *$ & 0.00358 & -0.05018 & 0.00180 \\
\hline Change of house & $0.00471 * * *$ & $0.05517 * * *$ & 0.00024 & $0.01104 * *$ & $0.10886 * * *$ & $0.00929 * * *$ \\
\hline Rehabilitation treatment & $0.00219 * * *$ & $0.03219 * * *$ & $0.00034 * *$ & $0.01142 *$ & -0.01793 & $0.00917 * * *$ \\
\hline Impairment certificate & -0.00033 & 0.00890 & 0.00018 & 0.00420 & $-0.04329 * *$ & $-0.00263 *$ \\
\hline Number of days at hospital & 0.00002 & $0.00083 * *$ & $0.00001 * * *$ & 0.00016 & 0.00057 & $0.00009 *$ \\
\hline Number of disabilities & 0.00066 & -0.00588 & -0.00002 & 0.00510 & $-0.02957 * * *$ & -0.00019 \\
\hline \multicolumn{7}{|l|}{ Disabilities for: } \\
\hline Seeing & $-0.00151 * *$ & $-0.04042 * * *$ & $-0.00043 * * *$ & $-0.01366 * *$ & 0.01335 & -0.00072 \\
\hline Hearing & $-0.00153 * *$ & $-0.05571 * * *$ & $-0.00045 * * *$ & $-0.02302 * * *$ & $-0.02844 * *$ & $-0.00254 *$ \\
\hline Communicating & $-0.00224 *$ & $0.06029 * *$ & $0.00097 * * *$ & -0.01126 & $0.07989 * *$ & 0.00320 \\
\hline Remembering/Executing & 0.00029 & $-0.05308 * * *$ & -0.00018 & $-0.02424 * *$ & -0.00584 & -0.00405 \\
\hline Relating & $-0.00272 * *$ & -0.00225 & -0.00019 & 0.00680 & -0.06217 & -0.00614 \\
\hline Number of PADL & -0.00037 & $0.04329 * * *$ & $0.00040 * * *$ & -0.00919 & 0.02322 & 0.00225 \\
\hline $\mathrm{PADL}=2$ & -0.00095 & $-0.06284 * * *$ & $-0.00058 * * *$ & -0.00059 & 0.04489 & -0.00264 \\
\hline $\mathrm{PADL}=3$ & -0.00173 & $-0.08432 * * *$ & $-0.00064 * * *$ & 0.00071 & 0.01191 & -0.00239 \\
\hline PADL $>=4$ & -0.00040 & -0.05396 & -0.00064 & $0.03162 *$ & $0.13315^{* *}$ & 0.00568 \\
\hline Number of IADL & 0.00027 & $0.04870 * * *$ & $0.00035 * * *$ & $0.00103 * *$ & $0.09254 * * *$ & $0.00345 * * *$ \\
\hline $\mathrm{IADL}=2$ & $0.00458 * * *$ & $0.07634 * * *$ & 0.00030 & $0.01559 * *$ & $0.11944 * * *$ & $0.02318 * * *$ \\
\hline IADL =3 & 0.00288 & 0.02847 & -0.00011 & $0.05804 * * *$ & $0.13884 * * *$ & $0.03861 * * *$ \\
\hline IADL $>=4$ & $0.00484 * *$ & $0.09908 * * *$ & 0.00022 & $0.05569 * * *$ & $0.16894 * * *$ & $0.04039 * * *$ \\
\hline \multicolumn{7}{|l|}{ Severity } \\
\hline \multicolumn{7}{|l|}{ No severe/ Moderate } \\
\hline severe & -0.00365 & $0.04748 * *$ & -0.00054 & 0.00039 & $0.13372 * * *$ & -0.00338 \\
\hline Very severe & -0.00114 & $0.07047 * * *$ & $0.00069 *$ & $0.01459 * *$ & $0.12808 * * *$ & 0.00452 \\
\hline \multicolumn{7}{|l|}{ Can not do the } \\
\hline activity & -0.00113 & 0.00618 & 0.00025 & -0.00581 & $0.07745 * * *$ & 0.00378 \\
\hline \multicolumn{7}{|l|}{ Forecast } \\
\hline Recoverable (with & & & & & & \\
\hline restrict) & 0.00105 & $0.08309 * * *$ & 0.00015 & $0.01841 * *$ & 0.01875 & 0.00269 \\
\hline Stable & 0.00053 & $0.05248 * * *$ & $0.00030 * *$ & $0.01300 * * *$ & $0.08167 * * *$ & $0.00611 * * *$ \\
\hline Can go worse & 0.00098 & $0.06402 * * *$ & $0.00036 * * *$ & $0.01332 * * *$ & $0.10820 * * *$ & $0.00774 * * *$ \\
\hline Do not know & 0.00125 & 0.02521 & 0.00003 & 0.00891 & 0.04114 & $0.00413 *$ \\
\hline \multicolumn{7}{|c|}{ Autonomous Communities } \\
\hline Andalucia & -0.00021 & 0.09699 & -0.00052 & 0.02612 & $0.20844 * *$ & -0.01047 \\
\hline Aragón & 0.00128 & 0.10168 & -0.00043 & 0.06066 & $0.15998 * *$ & -0.00471 \\
\hline Asturias & 0.00248 & 0.11893 & -0.00029 & 0.01573 & $0.17076 *$ & $-0.01240 *$ \\
\hline Baleares & 0.00145 & 0.04913 & -0.00018 & 0.02813 & 0.14065 & -0.00636 \\
\hline Canarias & -0.00196 & -0.02436 & $-0.00054 *$ & 0.01269 & 0.10489 & -0.00879 \\
\hline Cantabria & -0.00483 & 0.11329 & -0.00027 & 0.01817 & $0.28805 * * *$ & -0.01030 \\
\hline a Mancha & -0.00057 & 0.03 & -0.00050 & 23 & $0.18433 * *$ & -0.00950 \\
\hline Cast & -0.00039 & & -0.0 & & $65 * *$ & 757 \\
\hline Cata & & & -0.0 & $89 *$ & $654 *$ & -0.01484 \\
\hline nadura & 0.00 & $0.12079 *$ & 0.0 & 358 & $0.16979 * *$ & -0.00242 \\
\hline Galicia & -0.00073 & 0.01937 & -0.00 & 0.01698 & 0.13898 & $-0.01307 *$ \\
\hline Madrid & -0.00166 & 0.03145 & -0.00038 & 0.04002 & 0.01111 & $-0.01354 * *$ \\
\hline Murcia & -0.00021 & 0.09130 & $-0.00065 * *$ & 0.01170 & $0.20924 * *$ & -0.01013 \\
\hline Navarra & -0.00104 & 0.12821 & 0.00070 & 0.02104 & $0.34316 * * *$ & 0.00200 \\
\hline Rioja & -0.00156 & -0.00800 & -0.00051 & 0.07434 & 0.12745 & -0.00543 \\
\hline País Vasco & -0.00012 & 0.01792 & $-0.00059 * *$ & 0.02318 & 0.09353 & -0.00614 \\
\hline C. Valenciana & 0.00067 & 0.08485 & -0.00041 & 0.00918 & $0.17874 *$ & -0.00988 \\
\hline Ceuta & 0.00032 & 0.04962 & -0.00028 & -0.04721 & $0.30329 * *$ & -0.00960 \\
\hline $\mathrm{N}$ & 133 & 2.270 & 229 & 429 & 3.496 & 773 \\
\hline & & 0.3370 & & & 0.3358 & \\
\hline Log Likelihood & & -3853.4436 & & & -7127.7043 & \\
\hline
\end{tabular}


Table 7. Bourguignon Model. Second Step hours equations. All Sample

\begin{tabular}{|c|c|c|c|}
\hline & Formal Care & Informal Care & Formal \& Informal \\
\hline & p-value & p-value & p-value \\
\hline Male & 0.0156 & $0.2363 * * *$ & 0.1372 \\
\hline \multicolumn{4}{|l|}{ Age } \\
\hline $50-59$ & -0.2063 & 0.0749 & 0.2715 \\
\hline $60-69$ & 0.4105 & 0.1125 & 0.0877 \\
\hline $70-79$ & 0.3300 & 0.2055 & 0.3502 \\
\hline $80-99$ & $0.9303 *$ & $0.3031 *$ & 0.3202 \\
\hline \multicolumn{4}{|l|}{ Marital status } \\
\hline Married & -0.0177 & -0.1440 & 0.1851 \\
\hline Widowed & 0.0858 & -0.1295 & 0.0487 \\
\hline Divorced & 0.2200 & $-0.4956 * *$ & -0.6160 \\
\hline Number of children 13-17 years & 0.2923 & $-0.1119 * *$ & -0.1668 \\
\hline \multicolumn{4}{|l|}{ Monthly household income } \\
\hline$<390,6 €$ & $-0.4642 *$ & -0.0124 & $-0.5683 * * *$ \\
\hline $390,6 €-1.171,97 €$ & $-0.5057 *$ & $0.1441 *$ & -0.1674 \\
\hline $1.171,97 €-1.953,29 €$ & -0.1552 & -0.0841 & -0.3136 \\
\hline $1.953,29 €-3.906,58 €$ & $-1.8793 * * *$ & -0.1186 & -0.3517 \\
\hline$>3.906,58 €$ & -1.8579 & -0.5108 & 0.2611 \\
\hline Number household adults & $0.4778 * * *$ & $0.0939 * * *$ & 0.0746 \\
\hline \multicolumn{4}{|l|}{ Size of municipality } \\
\hline$<10.000$ & $-0.5725 * * *$ & $-0.4337 * * *$ & $-0.5868 * * *$ \\
\hline $10.000-50.000$ & $-0.7358 * * *$ & $-0.4183 * * *$ & $-0.5905 * * *$ \\
\hline $50.000-500.000$ & $-0.3925 * *$ & $-0.3240 * * *$ & -0.2725 \\
\hline \multicolumn{4}{|l|}{ Illnesses } \\
\hline Mental illness & 0.2077 & $0.3310 * * *$ & 0.0626 \\
\hline Arthritis & -0.1852 & $-0.1048 * *$ & -0.1937 \\
\hline Muscular distrophy & -0.0100 & -0.0386 & 0.0685 \\
\hline Multiple scelerosis & -0.0235 & $0.2390 *$ & 0.0674 \\
\hline Stroke & 0.1722 & $0.1509 * *$ & -0.1538 \\
\hline Cerebral palsy & 0.5123 & -0.0842 & -0.1030 \\
\hline Dementia & 0.5859 & $0.3721 * * *$ & 0.2455 \\
\hline Parkinsonism & 0.1306 & 0.0614 & -0.1374 \\
\hline Change of house & 0.1283 & $0.2130 * * *$ & 0.1801 \\
\hline Rehabilitation treatment & -0.1957 & $-0.1590 * *$ & $-0.2076 *$ \\
\hline Impairment certificate & -0.0717 & 0.0825 & $0.4072 * *$ \\
\hline Number of days at hospital & -0.0020 & $0.0060 * * *$ & -0.0005 \\
\hline Number of disabilities & -0.0600 & 0.0398 & -0.0367 \\
\hline \multicolumn{4}{|l|}{ Disabilities for: } \\
\hline Seeing & 0.0148 & 0.0524 & $0.2500 * *$ \\
\hline Hearing & 0.0170 & 0.0018 & 0.1182 \\
\hline Communicating & 0.6253 & 0.1529 & 0.0806 \\
\hline Remembering/Executing & -0.7409 & -0.2084 & -0.0767 \\
\hline Relating & 0.7063 & $0.2731 *$ & $0.4757 *$ \\
\hline Number of PADL & 0.1050 & 0.0138 & 0.0501 \\
\hline $\mathrm{PADL}=2$ & -0.1783 & $0.1540 * *$ & $0.4354 * *$ \\
\hline PADL $=3$ & -0.0396 & 0.0455 & 0.4654 \\
\hline $\mathrm{PADL}>=4$ & 0.0690 & $0.3743^{* *}$ & 0.6463 \\
\hline Number of IADL & $0.2697 * *$ & $0.0721 * *$ & 0.1314 \\
\hline $\mathrm{IADL}=2$ & -0.0062 & 0.0383 & 0.0998 \\
\hline $\mathrm{IADL}=3$ & -0.4309 & -0.0213 & 0.0666 \\
\hline $\mathrm{IADL}>=4$ & -0.2877 & -0.0573 & 0.0029 \\
\hline \multicolumn{4}{|l|}{ Severity } \\
\hline No severe/ Moderate severe & 0.3290 & $-0.6577 * *$ & -0.8707 \\
\hline Very severe & 0.4280 & 0.2057 & 0.0308 \\
\hline Can not do the activity & 0.0323 & 0.0926 & 0.3018 \\
\hline \multicolumn{4}{|l|}{ Forecast } \\
\hline Recoverable (with restrict) & -0.2136 & -0.1672 & $-0.6355 * * *$ \\
\hline Stable & -0.0039 & $-0.1752 * * *$ & -0.1568 \\
\hline Can go worse & -0.2250 & $-0.2242 * * *$ & $-0.2233 *$ \\
\hline Do not know & -0.0828 & 0.0898 & -0.0849 \\
\hline$\overline{\mathrm{M} 0}$ & 1.6593 & 0.1196 & $2.4962 *$ \\
\hline M1 & -0.0716 & $1.5327 * *$ & $2.5480 * *$ \\
\hline M2 & $2.6405^{* *}$ & -0.2527 & $1.4934 * *$ \\
\hline M3 & 0.7403 & $-1.4936 * * *$ & -0.0629 \\
\hline Constant & 2.5144 & $3.1846 * * *$ & $5.2245 * * *$ \\
\hline $\mathrm{N}$ & 562 & 6.216 & 1.002 \\
\hline$\sigma$ & 1.1802 & 1.6559 & 1.5374 \\
\hline
\end{tabular}

Omitted variables: age 40-49, single, missing household income, number of children less 13 years old, size of municipality $>500.000$ inhabitants. ( $\left.\mathrm{p}<0.10 ;{ }^{* *} \mathrm{p}<0.05 ;{ }^{* * *} \mathrm{p}<0.01\right)$ 
Table 8. Bourguignon Model by gender. Second Step hours equations.

\begin{tabular}{|c|c|c|c|c|c|c|}
\hline & \multicolumn{3}{|c|}{ MALE } & \multicolumn{3}{|c|}{ FEMALE } \\
\hline & FORMAL & INFORMAL & F\&I & FORMAL & INFORMAL & F\&I \\
\hline & coef & coef & coef & coef & coef & coef \\
\hline \multicolumn{7}{|l|}{ Age } \\
\hline $50-59$ & -2.9373 & 0.1768 & -0.0608 & 0.3335 & 0.0820 & 0.8144 \\
\hline $60-69$ & -1.4133 & -0.0147 & -0.9486 & 0.5534 & 0.2288 & 0.6386 \\
\hline $70-79$ & 0.0427 & 0.1842 & -0.5608 & 0.8463 & $0.2496 *$ & 0.5045 \\
\hline $80-99$ & 0.9182 & 0.2723 & -0.7933 & $1.4643 * *$ & $0.3396 * *$ & 0.4459 \\
\hline \multicolumn{7}{|l|}{ Marital status } \\
\hline Married & -0.8848 & -0.2407 & 0.6276 & $-0.4648 *$ & -0.1456 & 0.1833 \\
\hline Widowed & -0.2861 & $-0.4495 * * *$ & 0.0173 & -0.2171 & -0.0788 & 0.2680 \\
\hline Divorced & 1.8218 & $-0.7500 *$ & -1.3157 & 0.2209 & $-0.4071 *$ & -0.2915 \\
\hline Number household adults & 0.8305 & -0.0192 & 0.0681 & 0.2230 & $0.1234 * * *$ & 0.2305 \\
\hline \multicolumn{7}{|l|}{ Size of municipality } \\
\hline$<10.000$ & -1.4948 & $-0.7745 * * *$ & $-0.8901 *$ & $-0.6409 * *$ & $-0.2913 * *$ & -0.2527 \\
\hline $10.000-50.000$ & -2.2071 & $-0.7388 * * *$ & -0.5635 & -0.5948 & $-0.2681 * *$ & $-0.3790 *$ \\
\hline $50.000-500.000$ & -1.8260 & $-0.5934 * * *$ & -0.3301 & -0.3147 & $-0.2578 * *$ & -0.1940 \\
\hline \multicolumn{7}{|l|}{ Illnesses } \\
\hline Mental illness & 1.3990 & 0.3808 & 0.5890 & 0.5363 & $0.3333 * * *$ & -0.1060 \\
\hline Arthritis & -0.2506 & $-0.2078 * *$ & 0.0928 & -0.1789 & -0.0514 & -0.1033 \\
\hline Muscular distrophy & 1.1947 & 0.0872 & -0.6482 & 0.0634 & -0.0985 & -0.1043 \\
\hline Multiple scelerosis & 1.5419 & 0.3503 & -1.9274 & -0.0978 & 0.1256 & 0.0827 \\
\hline Stroke & 0.0332 & $0.1998 *$ & -0.3956 & 0.1317 & $0.1513 *$ & -0.2436 \\
\hline Cerebral palsy & 0.0000 & -0.1327 & -0.0719 & $0.5954 * *$ & -0.0216 & 0.0240 \\
\hline Dementia & 1.1510 & $0.4544 * *$ & 0.2760 & 0.2765 & $0.3967 * * *$ & 0.2859 \\
\hline Parkinsonism & 0.0774 & 0.1820 & -0.1885 & 0.0874 & -0.0871 & -0.4393 \\
\hline Change of house & 1.3829 & 0.2902 & 0.0239 & 0.2317 & 0.1632 & 0.0981 \\
\hline Rehabilitation treatment & -0.7847 & $-0.2287 * *$ & 0.1476 & 0.0545 & -0.1454 & $-0.5239 * *$ \\
\hline Impairment certificate & 0.0727 & 0.0181 & 0.1676 & -0.2134 & 0.1141 & $0.5179 * * *$ \\
\hline Number of days at hospital & -0.1440 & $0.0099 * *$ & -0.0003 & 0.0013 & $0.0039 * * *$ & -0.0044 \\
\hline Number of disabilities & 0.1157 & 0.0549 & -0.0535 & -0.0750 & 0.0212 & -0.0592 \\
\hline \multicolumn{7}{|l|}{ Disabilities for: } \\
\hline Seeing & 0.1371 & 0.1687 & 0.2501 & 0.0190 & 0.0298 & $0.4595 * *$ \\
\hline Hearing & -0.8831 & -0.0645 & -0.1396 & -0.0680 & 0.0601 & 0.1678 \\
\hline Communicating & 0.4602 & 0.0050 & 0.4393 & 0.3873 & $0.2653 * *$ & -0.0772 \\
\hline Remembering/Executing & -1.6268 & -0.1841 & -0.0896 & -0.8142 & $-0.2460 *$ & -0.5145 \\
\hline Relating & -1.0161 & $0.4249 * *$ & -0.2957 & 0.9508 & 0.2568 & $1.3728 * * *$ \\
\hline Number of PADL & -0.2062 & 0.0358 & 0.0445 & 0.1406 & 0.0246 & 0.0335 \\
\hline PADL = 2 & 0.6559 & 0.1882 & 0.4499 & -0.2786 & 0.1450 & $0.6845 * *$ \\
\hline PADL $=3$ & 2.0003 & -0.0605 & 0.7031 & -0.2560 & 0.0932 & 0.5911 \\
\hline PADL > = 4 & 1.5722 & 0.3710 & 1.1609 & 0.0050 & 0.3614 & 0.5951 \\
\hline Number of IADL & 0.1873 & 0.0920 & 0.0638 & $0.3034 * *$ & 0.0716 & 0.1195 \\
\hline $\mathrm{IADL}=2$ & 2.0658 & -0.0120 & -0.1142 & -0.0973 & 0.1255 & 0.2153 \\
\hline IADL =3 & 2.5385 & 0.0604 & -0.5312 & -0.3497 & -0.0420 & 0.2833 \\
\hline IADL >=4 & 4.1343 & -0.0704 & 0.0497 & 0.0137 & -0.0479 & -0.3884 \\
\hline \multicolumn{7}{|l|}{ Severity } \\
\hline No severe/ Moderate severe & -1.0563 & $-1.8155 * * *$ & - & 0.2441 & -0.1415 & $-1.4401 *$ \\
\hline Very severe & - & 0.1765 & 0.0542 & 0.4651 & 0.2504 & -0.4437 \\
\hline Can not do the activity & 0.7842 & -0.1067 & 0.6060 & -0.1902 & 0.1611 & 0.4053 \\
\hline \multicolumn{7}{|l|}{ Forecast } \\
\hline Recoverable (with restrict) & 1.4926 & -0.2449 & -0.5119 & -0.1336 & $-0.1607 *$ & $-0.4689 *$ \\
\hline Stable & 0.2471 & $-0.2836 * * *$ & -0.1729 & 0.1342 & $-0.1315 *$ & $-0.2190 *$ \\
\hline Can go worse & 0.2251 & $-0.2224 * *$ & 0.2269 & -0.1842 & $-0.2411 * * *$ & $-0.4140 * * *$ \\
\hline Do not know & -2.3218 & -0.0483 & 0.3054 & 0.0075 & 0.1318 & -0.3301 \\
\hline M0 & -2.7132 & -0.8195 & 1.7240 & -0.1733 & 0.7931 & $3.2119 *$ \\
\hline M1 & -0.1422 & 1.4500 & 0.8488 & 0.7399 & $1.3849 * *$ & $3.0070 * *$ \\
\hline M2 & 6.8068 & $-0.6626 * *$ & 1.5505 & 0.5136 & 0.1297 & 2.3479 \\
\hline M3 & 4.2927 & -0.8150 & -0.2497 & 0.1427 & $-1.6555 *$ & -0.8997 \\
\hline Constant & 0.3996 & $5.3269 * * *$ & 4.9881 & -0.9701 & $2.4456 * *$ & $7.6958 * * *$ \\
\hline$\overline{\mathrm{N}}$ & 98 & 2.052 & 230 & 464 & 4.164 & 772 \\
\hline$\sigma$ & 0.7948 & 1.6475 & 1.4616 & 1.2286 & 1.6490 & 1.5236 \\
\hline
\end{tabular}

Omitted variables: age 40-49, single, size of municipality $>500.000$ inhabitants. ( ${ }^{*} \mathrm{p}<0.10{ }^{* * *} \mathrm{p}<0.05{ }^{* * * *} \mathrm{p}<0.01$ ) 
Table 9. Bourguignon Model by age group. Second Step hours equation.

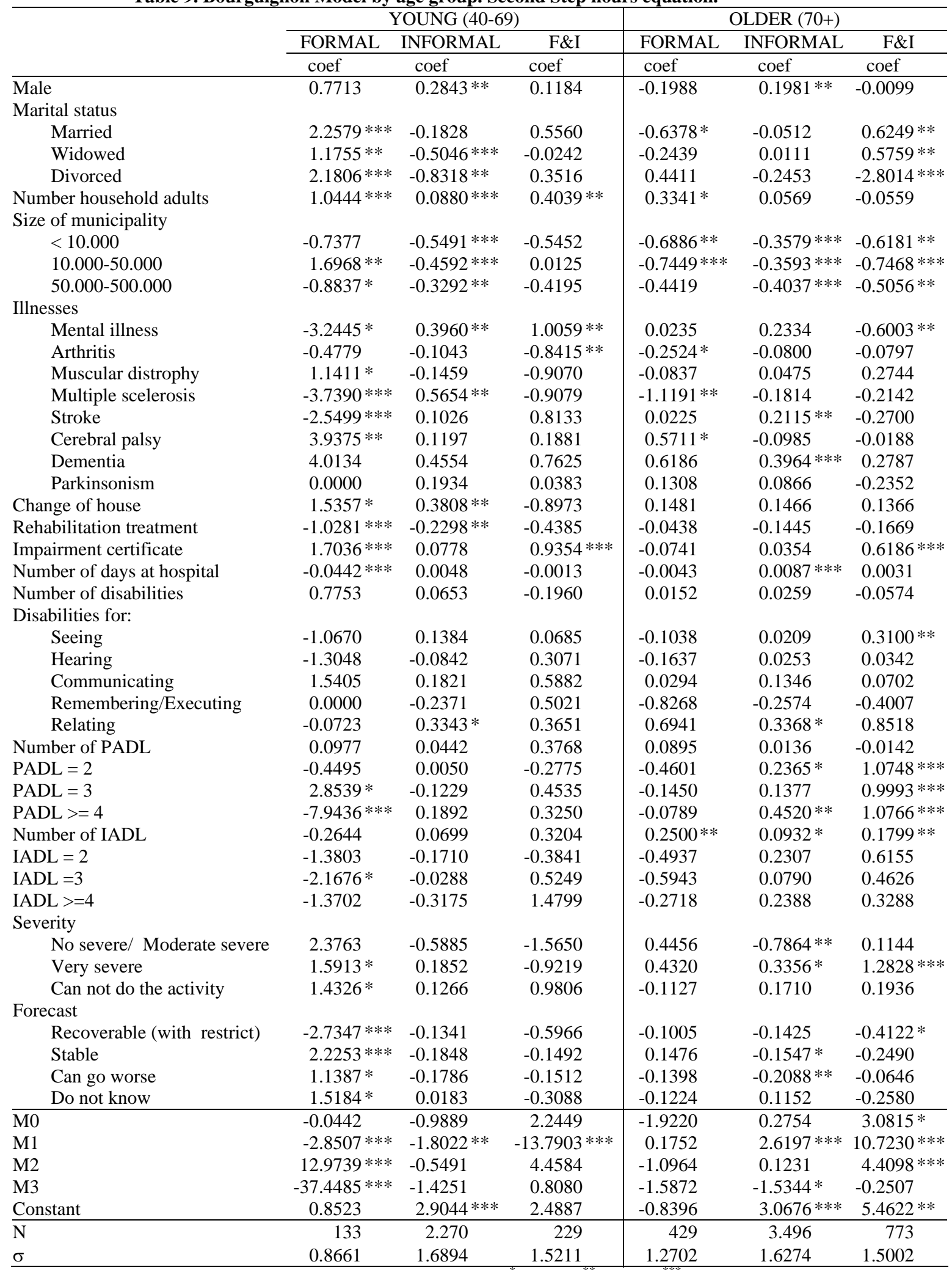

Omitted variables: single, size of municipality $>500.000$ inhabitants. $\left({ }^{*} \mathrm{p}<0.10 ;{ }^{* *} \mathrm{p}<0.05 ;{ }^{* * *} \mathrm{p}<0.01\right)$ 
Table 10. Coverage Index of Social Services for Dependent People. 1999

\begin{tabular}{|c|c|c|c|c|c|}
\hline & Home Care & Tele Care & Day Centers & Public Residential Homes & Private Residential Homes \\
\hline Andalucía & 2.04 & 1.55 & 0.02 & 1.10 & 1.44 \\
\hline Aragón & 2.44 & 1.67 & 0.09 & 0.89 & 3.22 \\
\hline Asturias & 1.79 & 0.89 & 0.12 & 1.16 & 2.23 \\
\hline Baleares & 2.78 & 0.72 & 0.07 & 0.70 & 1.08 \\
\hline Canarias & 1.88 & 0.22 & 0.22 & 2.39 & - \\
\hline Cantabria & 1.55 & 0.26 & 0.23 & 0.94 & 2.97 \\
\hline C. León & 2.48 & 1.61 & 0.17 & 1.83 & 3.39 \\
\hline C. Mancha & 2.55 & 1.85 & 0.11 & 1.62 & 2.38 \\
\hline Cataluña & 1.30 & 0.57 & 0.24 & 1.52 & 2.40 \\
\hline C. Valenciana & 2.16 & 1.99 & 0.04 & 1.15 & 1.00 \\
\hline Extremadura & 4.86 & 0.66 & 0.32 & 1.28 & 1.65 \\
\hline Galicia & 1.35 & 0.29 & 0.02 & 0.65 & 1.28 \\
\hline Madrid & 1.89 & 1.01 & 0.14 & 1.55 & 1.38 \\
\hline Murcia & 1.64 & 1.16 & 0.16 & 0.90 & 0.91 \\
\hline Navarra & 3.02 & 3.55 & 0.12 & 1.29 & 3.56 \\
\hline País Vasco & 2.85 & 1.16 & 0.28 & 1.77 & 2.48 \\
\hline La Rioja & 2.84 & 0.82 & 0.16 & 1.52 & 3.78 \\
\hline Ceuta & 1.76 & 1.43 & - & 1.34 & - \\
\hline Melilla & 3.04 & 2.04 & - & 1.41 & 2.19 \\
\hline España & 2.07 & 1.07 & 0.13 & 1.33 & 1.86 \\
\hline
\end{tabular}

Source: Observatorio de Personas Mayores (Imserso, 2000).

Coverage Index $=($ Number of users $/$ Population $\geq 65$ years $) * 100$. 